$10 \mathrm{May}, 1892$.

GEORGE BERKLEY, President, in the Chair.

Mr. George Benkley, President, before the commencement of the ordinary business, regretted to announce the death of Lord Bramwell, who, as an honorary member, had for many years taken a deep interest in the welfare of the Institution. The distinction of honorary membership, which he had reason to know Lord Bramwell valued highly, was, in part at least, due to his labours in connection with the Royal Commission on Metropolitan Sewage Discharge-duties which he had fulfilled with great ability. The Council tendered to his brother, Sir Frederick Bramwell, one of their esteemed Past-Presidents, their sympathy on this sad occasion; and he ventured to suggest that the members should accept the expression of feeling which had been adopted by the Council in the foregoing terms.

(Paper No. 2619.)

"The Distribution and Measurement of Illumination."

By Alexander Pelham Trotter, B.A., Assoc. M. Inst. C.E.

\title{
SECTION I.-INTRODUCTORY.
}

Light being an expenditure of energy, "candle-power" is an accurate term, since it is the measure of the rate of expenditure of energy; and the art of illumination is therefore, in a very definite sense, a matter which comes within the province of civil engineers, since it is the art of directing this power for the use and convenience of man. The study of light, its nature and laws, belongs to the science of optics, but we may look to optical treatises in vain for any useful information on the present subject. Illumination, if alluded to at all, is passed over in a few lines. There is at present no recognized unit by which it may be measured; the geometrical laws of its natural distribution are not commonly xinderstood; and the specification of a required illumination of a street or of a railway-station would puzzle most contractors 
When illumination is required, it ought to be possible to express intelligibly how much is wanted, and, a specification being given, it ought to be known how to execute it.

The photometry of lights, that is to say the measurement of candle-power, will only be alluded to briefly in the present Paper, for the purpose of sketching the development of photometers. There is very little to be said about this kind of photometry, unless from the point of view of testing the quality of gas, or from the point of view of the physicist, whose methods of measurement and analysis do not concern the present subject.

The English and French languages are remarkably rich in words connected with light, while such terms as illumination, brilliance, brightness, intensity and luminosity are generally employed by different writers to express different ideas, and are often used in a confused and vague way.

\section{Definition $\triangle$ ND Unit.}

In the present Paper, the word light will be used to mean the luminous radiation emitted from a flame or incandescent surface, or reflected from a surface. It is measured as an intensity in any direction as candle-power. It is measured as a quantity by the product of the solid angle into the mean candle-power. The total quantity of light emitted by a luminous point in all directions is $4 \pi$ times the mean candle-power. When light falls upon a surface, that surface is said to be illuminated. The illumination depends simply upon the quantity of light falling upon a given surface, and has nothing to do with the nature of that surface, just as rainfall is independent of the nature of the soil. Some of the light may be absorbed, and some may be transmitted. The brightness resulting from illumination has been called luminosity by Captain Abney.

Illumination consists of two factors, candle-power and distance. It is only necessary to allude briefly to existing standards of candle-power. These are in a very unsatisfactory condition, partly because the centimetre-gramme-second system cannot be extended to them. The English Parliamentary candle is not a more scientific or accurate standard than the barley-corn, of which three went to an inch. The unit which will sooner or later be adopted, ${ }^{1}$ will probably aim at reproducing the mean value of the standard candle, of which six go to a pound, and which ought to consume 120 grains of sperm per hour. The relative merits of the Methven

1 A joint Committee has been appointed to consider this question, by the Board of Trade, the London County Council, and the Gas Companies. 
standard, which takes a sample patch of a gas-flame, or a pentanelamp, need not be considered at present; they are fortunately of about the same magnitude as the French bougie decimale, onetenth of the old carcel, and as the German vereinskerze, a paraffincandle, 12 to a kilogram.

In the present Paper, the standard Parliamentary candle will be taken as the unit of candle-power.

A unit of illumination was proposed in France in 1882, and is self-explained by its name " carcel-metre." The carcel-metre has been shown by Mr. Preece ${ }^{1}$ to be equal to a standard candle at 1.058 foot, and the name "lux" was proposed by him for the English equivalent, at the Paris Electrical Congress in 1889. It is owing to the general apathy with which the subject of this Paper has been regarded, rather than to a disinclination to twist British national measurements to fit the metric system, that neither this unit nor its name have come into general use. The bougie-metre, to which some French writers refer, is equal to onetenth of a candle at a distance of 1.058 foot, or to one candle at $\sqrt{10} \times 1.058=3.35$ feet. The bougie-metre is a very feeble illumination, and is practically that which is to be found near a good street-lamp, having a 13-candle-power burner at a height of 12 feet from the ground. Convenient as the metric system is, its advantage for many engineering purposes is not yet convincing, and as the heights of lamp-posts and the width of streets are measured in feet, the candle-foot, that is, the illumination produced by one standard candle at a distance of 1 foot, will be taken in the present Paper as the unit of illumination. A candle-foot is 0.893 of a lux or carcel-metre, and a lux is 1.12 candle-foot.

The candle-foot is a very convenient and "comfortable" illumination." It is, for most people, the best illumination for reading, and is to be found on most well-lighted dining-tables and billiardtables. More than 2 candle-feet is seldom attained in artificial illumination. One candle at 1 foot is equivalent to four candles at 2 feet, nine candles at 3 feet, \&c.; but to say off-hand how many candle-feet are produced by a sixteen-candle lamp, at a distance of 8 feet, is rather puzzling at first. The illumination is $\frac{16}{8^{2}}=0 \cdot 25$ candle-foot.

1 Proceedings Royal Society, vol. xxxvi. p. 276.

2 The illumination on the President's desk, at The Institution of Civil Engincers, is about 0.8 candle-foot. 
The illumination produced, in candle-feet or in bougie-metres, by any given candle-power at any given distance, may be found on a slide-rule thus :-

Fig. 1.

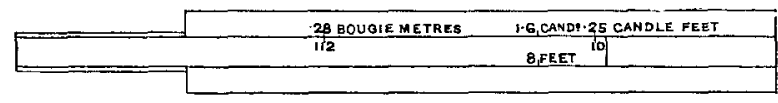

'The value of any illumination in bougie-metres, for the sake of comparison with French work, may be found by the formula,-$n$ candles at $1.058 \times \sqrt{n}$ feet. Thus 0.7 candle-power at $2 \cdot 8$ feet, or seven-candle-power at $8 \cdot 86$ feet gives an illumination of 1 bougie-metre. This may be easily carried out on a slide-rule, thus :-

Fig. 2.

\begin{tabular}{|ccc|}
\hline & 0.7 CANOLE & 3 \\
\hline 1058 & 2,8 FEET & 8.86 \\
\hline IBOUGIE METRE & & \\
\hline
\end{tabular}

The conversion Tables given in the Appendix may be useful, as the square root and decimal places are rather puzzling, since the unit is so unfamiliar to most engineers that the decimal place cannot be guessed at.

The candle-foot, as alreary defined, assumes that the illuminated surface directly faces the source of light. If the surface is inclined to the direction of the rays of light, the illumination will diminish in proportion as the projected area of any part of the surface diminishes, when viewed from the source of light. The visible surface varies from unity, as seen full; to nothing, when seen on edge. The decrease varies, in fact, with the cosine of the angle of incidence. So little has the question of illumination been studied, that there is some ambiguity as to what is meant by the angle of incidence. It is a well-established convention among writers on optics, that the inclination between a ray and the perpendicular to a surface shall be called the angle of incidence. This angle will be frequently alluded to in this Paper, and it will be designated, where necessary, by $\theta$. A ray, proceeding horizontally, will therefore be of $90^{\circ}$ incidence; and a ray falling on the point immediately below a lamp, will be of $0^{\circ}$ incidence on the horizontal plane beneath it.

\section{Distribution of Illumination.}

The nature of the illumination of a horizontal plane by a light radiating uniformly in all directions, is the most simple, and at the same time the most useful and common problem for outdcor 
work. The candle-power of the light may be assumed to be constant, and need not enter into the matter. It will be taken as unity. The height of the lamp above the ground is also constant, and may be taken as unity. The illumination at any point on the plane varies inversely as the square of the distance from the light; that is, inversely as the square of the slant-height of the lamp. It also varies as the cosine of the angle of incidence. In Fig. 3 it will be seen that the height $\mathrm{A} B$ of the lamp being unity, the cosine of the angle of incidence $\mathrm{BAC}$ is measured by the ratio of the vertical height A B to the slant-height A C. The illumination will therefore be as the cube of the cosine of the incidence.

To obtain the illumination for special cases, it is sometimes convenient to use the simple trigonometrical ratios without reference to the angle of incidence. Thus the illumination at the point $\mathrm{C}$ may be reckoned as inversely proportional to the cube of the slant-height $\mathrm{AC}$, and proportional to the height $\mathrm{AB}$, and to the candle-power of the light.

$$
i=\frac{\mathrm{AB} \times \mathrm{c.p} .}{\mathrm{AC}^{3}}
$$

where $i$ is the illumination in candle-feet, c.p. the candle-power, and $A B$ and $A C$ distances measured in feet. Professor Henry Robinson, in a Paper read before the Association of Municipal and County Engineers, ${ }^{1}$ suggested as an approximation for determining the minimum illumination, that the simple horizontal distance, instead of the slant-distance, should be taken. This implies that the illumination varies as the cube of the cotan-

Fig. 3.

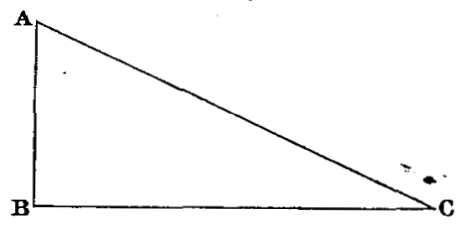
gent instead of the cosine. This approximation may suffice for very large angles, since both the cosine and the cotangent of $90^{\circ}$ are 0 , but the error becomes considerable even at $70^{\circ}$, for it is then 20 per cent. too great, while for small angles the cosine approaches unity, and the cotangent (being unity at $45^{\circ}$ ), approaches infinity.

The full curve in Fig. 4 represents the illumination at any point on the horizontal plane, by the height of the ordinate at that point, the maximum being unity. The value of the cubed cosine being of great importance in all such cases, and being somewhat

1 Proceedings, vol. xvii. p. 237. 
troublesome to calculate, Tables III and IV in the Appendix, together with the tangents of the angles of incidence, are given for convenience in rectangular plotting, as in Fig. 4.

It must be remembered that, while the curve in Fig. 4 shows very distinctly the gradual change in the illumination and allows very small differences to be appreciated, small changes cannot be estimated or even detected by the eye. Weber has shown that the intensity of visual sensation is not directly proportional to the luminous stimulus.' Illuminations, or indeed any other sensations, cannot be quantitatively compared, but equality can only be estimated, and that very roughly, compared with other measurements. An unpractised eye can with difficulty detect a difference of 8 per cent., as, for example, when two equal lights are placed at

Fig. 4.

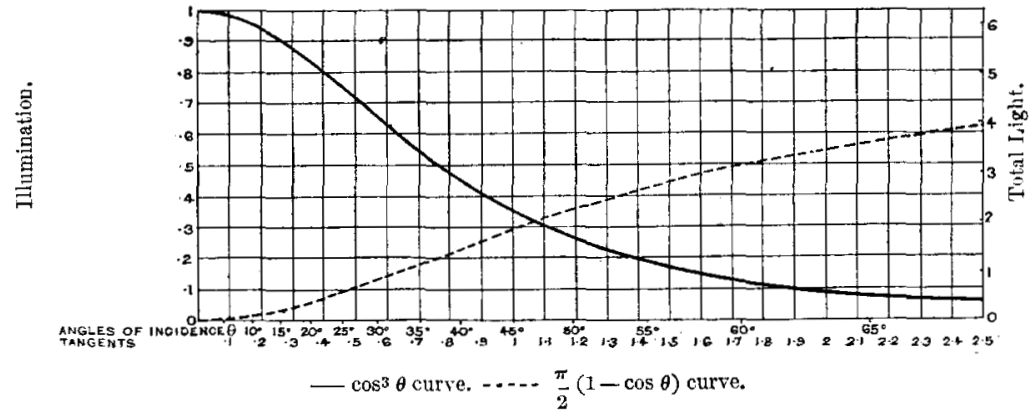

the ends of a 100-inch photometer bar, and the disk is displaced 1 inch from the middle. A little practice will enable 4 per cent. to be estimated, and figures pretending to an accuracy greater than 2 or 3 per cent. cannot, as a rule, be accepted, unless as the mean of a number of readings. But gradual changes of illumination, imperceptible though they may be, have an actual existence; and, though the Tables which accompany this Paper contain four-figure values, they need not be regarded as aiming at extreme accuracy, but are provided as a basis for other calculations. Illumination on a horizontal plane decreases so rapidly with the distance, that at an angle of incidence of about $37^{\circ}$ it falls off to one-half, at about $40^{\circ}$ to one-third, and at $62^{\circ}$ to one-tenth of the maximum.

1 Weber's law has been expressed thus: "The smallest change in the magnitude of a stimulus which we can appreciate through a change in our sensation, always bears the same proportion to the whole magnitude of the stimulus. . . . This law holds good within certain limits only; it fails when the stimulus is either above or below a certain range of intensity." Michael Foster, "Text Book of Physiology." 5th edition. Part IV. p. 1211. 


\section{Total Light.}

By a rather troublesome application of integral calculus, ${ }^{1}$ it may be shown that the cubic contents of a solid of revolution swept out by the revolution of the cosine-curve about its axis is $2 \pi$; but by simple geometry it is obvious that the total amount of light emitted in all directions from a radiant point is measured by the surface of the surrounding sphere of unit radius; this is equal to $4 \pi$. The amount falling on an indefinitely extended plane is therefore one-half of this, or $2 \pi$. It follows that if only a portion of the whole light be considered, it may be measured as the amount of the surface of the surrounding sphere; that is to say (the radius being unity) by the solid angle, subtended by that part of the sphere, or by any other surface, at the radiant point. This solid angle may be expressed trigonometrically, but it may be treated much more intelligibly by Archimedes' theorem, - that a sphere and its circumscribing cylinder being cut by planes perpendicular to the axis of the cylinder, the intercepted portions of the surface are equal in area. A quadrant of the sphere of unit radius being drawn (Fig. 5), let $\mathrm{OA}$ and $\mathrm{OB}$ be rays falling on the plane at the points $A$ and $B$. Erect perpendiculars from these points, and draw horizontal lines through the points at which they cut the quadrant, cutting the perpendiculars at $\mathrm{D}$ and $\mathrm{E}$. The lengths $A \mathrm{D}$ and $\mathrm{BE}$ represent the total light falling on the cones swept out by $\mathrm{OA}$ and O B. The dotted line in Fig. 4 is the curve obtained by this construction; the scale on the right gives the Fig. 5.

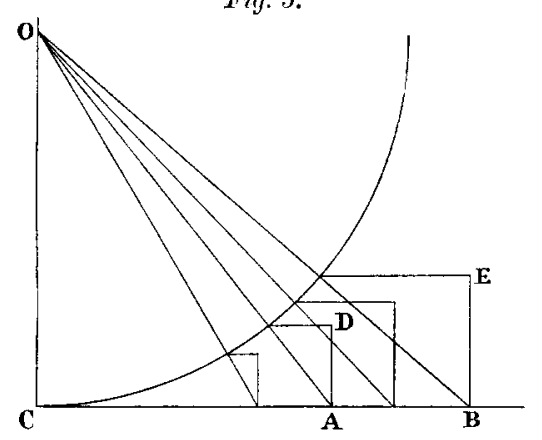

Construction hon Curve of Tónal Light. solid contents, or total light. At $60^{\circ}$, that is to say, a circle subtending $120^{\circ}$, one-half of the total light is received, and the curve continually approaches the value $2 \pi$.

A useful application of the knowledge of the total light received on a surface may be made in the measurement of the reflectingpower of a dead-white surface. There is no difficulty in testing the reflecting-power of a plane mirror or metallic reflector, since

" See appendix to a Paper by the Author on "A Dioptric System of Uniform Distribution of Light," Minutes of Proceedings Inst. C.E., vol. Ixxviii. p. 335. 
the reflected ray travels in a definite direction, and may be received on a photometer. But the light reflected from a deadwhite surface is diffused over a whole hemisphere, with a power very nearly proportional to the cosine of the angle of reflection, the deviation from this proportionality being due to imperfect smoothness or to partial polish. Because 1 square foot of white paper does not seem to be so useful a reflector as 1 square foot of looking-glass, it has been erroneously assumed that its reflectingpower is small. The estimation of the whole light reflected by measuring the light sent in one direction, appears at first to involve a troublesome application of integral calculus, but this is not the case. It is only necessary to take a disk of the reflecting material, and to place it behind a candle, so that its diameter subtends $120^{\circ}$ to the centre of the flame, to ensure that it receives exactly one-quarter of the whole light emitted, or one-half of that which is emitted in one hemisphere. If, after making allowance for the greater distance of the disk from the photometer, the candle-power is increased by 40 per cent., the reflecting-power of the material is 80 per cent. It is possible to intercept practically one-half of the light, by placing a large reflector very close to the flame. Measurements with good paper, plaster of Paris, and even white-wash, show that their reflecting-power is equal to that of ordinary looking-glass, viz., about 85 per cent.

White porcelain and enamelled iron are not so good, but, being glazed, they send a little light in a definite direction, and this makes a strict comparison difficult. The usefulness of a white reflector in practice depends almost entirely on the solid angle which it subtends to the light, and not, as is sometimes imagined, to its absolute dimensions.

\section{Examples of Distribution.}

By the practical application of the cosine law, the illumination which will be produced by any given arrangement of lights may be determined. The excellent illumination of Hyde Park Corner by gas-lamps has been brought about by merely adding to the number of lamps until the illumination was sufficient. When it was desired to illuminate the City by electric light, various experiments were made with temporary posts of different height, to try the "effect." The principal object of this Paper is to attempt to enable engineers to predetermine, specify for, and provide, a definite illumination.

The curve given in Fig. 4, and the table of values of $\operatorname{cosine}^{3} \theta$ (Appendix, Table III), enable the curves for the combined effect 
of a number of lamps to be determined by the simple addition of ordinates. Figs. $6,7,8$, and 9 give the component and resultant curves for four different arrangements. The first, Fig. 6 , consists of a row of lamps at a distance apart equal to their height, from the ground. The dotted lines show the cosine-curves, and the illumination produced by the neighbouring lamps is shown by the full lines. The first full line shows the resultant illumination of two lamps, and the next one above, a symmetrical portion being griven, represents the illumination due to three lamps. The other lines similarly show the additional effect of the more remote lamps. The illumination at the maximum is $1+$ twice the cubes of the

Fig. 6.

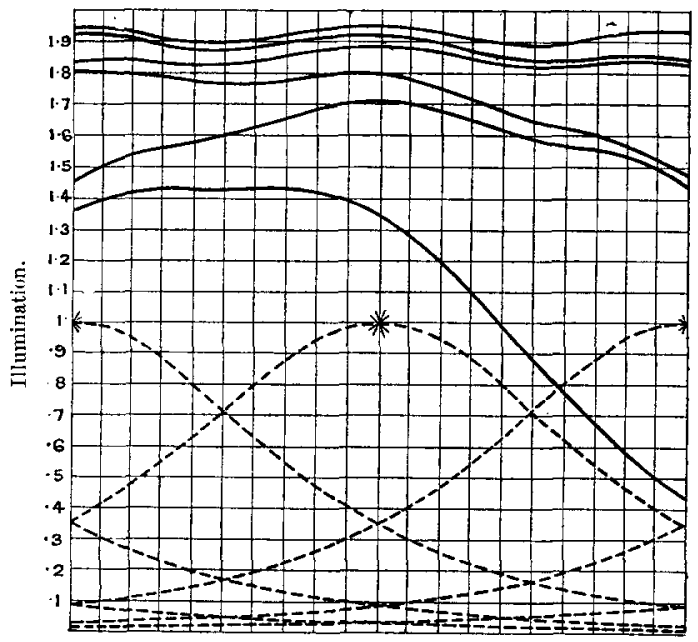

Resultant Illugmantion doe to Lights at a Distance apart Equal to their Height.

cosines of the angles whose tangents are $1,2,3,4, \&$ c., and is $1 \cdot 978$ when there are four lamps on each side. The minimum illumination is equal to twice the cube of the cosines of the angles whose tangents are $0 \cdot 5,1 \cdot 5,2 \cdot 5,3 \cdot 5, \& c$., and is equal to $1 \cdot 932$ for five lamps. The resultant curve is practically symmetrical about a horizontal line, and the mean illumination may be taken as the arithmetical mean of these values. It is bardly necessary to point out that the eye could scarcely detect any variation in the illumination thus produced, the difference being only $2 \frac{1}{4}$ per cent.

The next arrangement, Fig. 7 , is that of lamps placed at a distance apart equal to twice their height. The full lines show 
the effect of the neighbouring lamps. The maximum is $1 \cdot 219$, being $1+t$ wice the cubes of the cosines of angles whose tangents are

Fig. 7.

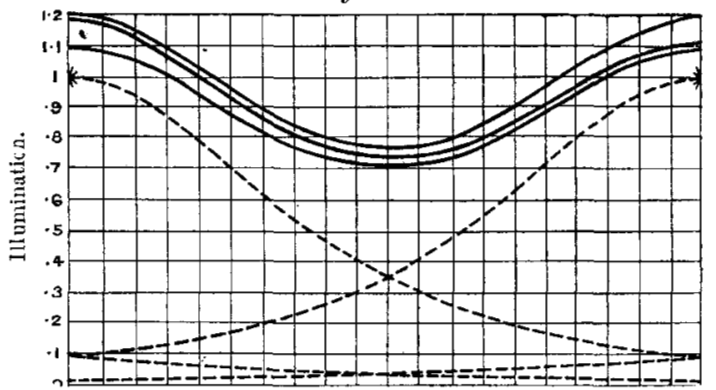

Resultant Illumination due to Lights at a distance apart equal to Twice their Heishat.

Fig. 8.

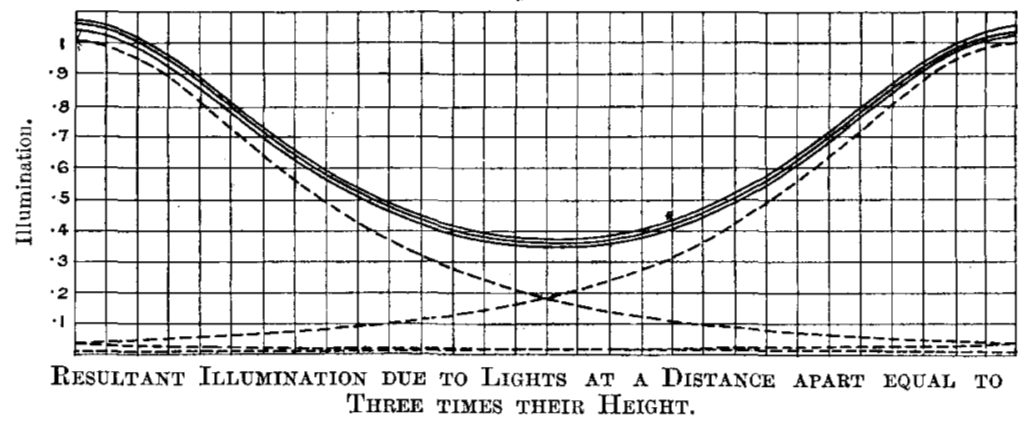

Fig. 9.

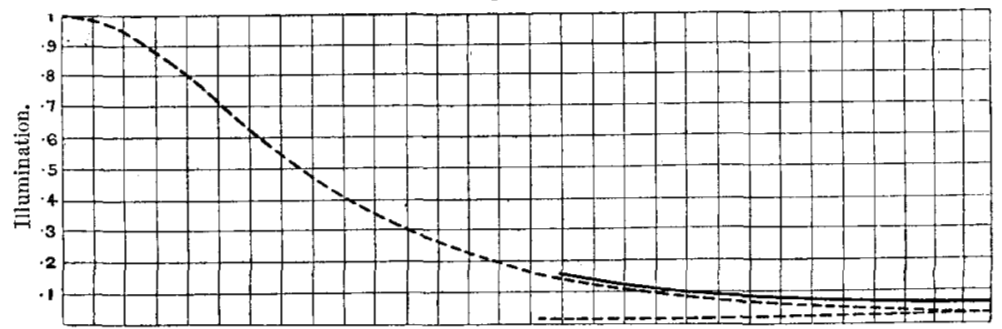

Resclitant Illumination due to lights at a Distance afart equal to Six Trues their Height.

$2,4,6,8$; and the minimum is $0 \cdot 7836$, being twice the cubes of the cosines of the angles whose tangents are $1,3,5,7$. The minimum is 35.8 per cent. less than the maximum. The mean is practically 
unity. In the next arrangement, Fig. 8 , the distance is three times the height. The maximum is 1.073 , and the minimum is 0.362 . The minimum is 63.8 per cent. less than the maximum. This variation is, of course, very marked, but is not nearly so apparent to the eye as is indicated by the curves. The last example, Fig. 9, is a common arrangement in street-lighting, the distance apart being six times the height of the lamps from the ground. The maximum is 1.01 , and the minimum is 0.0632 , the additional effect of only one lamp on each side has been considered. The variation is about 93.7 per cent. In the last two cases it is useless to consider the mean illumination.

Two practical modifications must be considered with regard to these results, one being the reflection by neighbouring houses, which assists the illumination of the region midway between the lamps, and the other being the shadow which is always to be found below a lamp, whether thrown by the gas-burners and the bottom

Fig. 10.

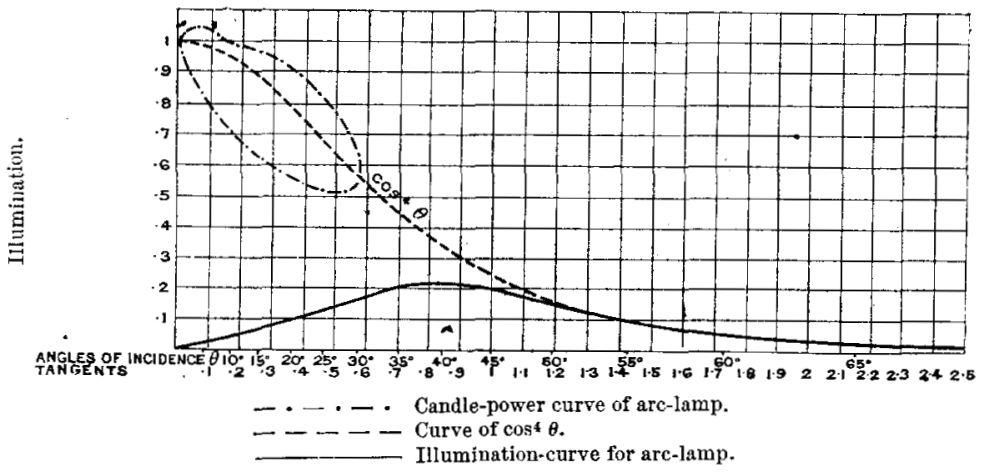

framing of the lantern, or by the lower carbon of an arc-lamp. The first of these modifications, though specially looked for by the Author in street-lighting measurements, was hardly appreciable except in cases of very feeble illumination. The second is a very marked feature with all street-lamps except those which are provided with good reflectors.

The light of ordinary gas-burners is not quite uniform in all horizontal directions, since the flame is not perfectly transparent, and there is some variation of candle-power at different angles with the horizon, ${ }^{1}$ but these are trifling compared with the natural

1 Radial measurements of gas-burners are given in "Practical Photometry," by W. J. Dibdin. 
variations which have been described. The light of arc-lamps is emitted in a very well-defined manner, and does not differ materially in different makes of lamps, provided that the ordinary pair of carbons are used with a continuous current. Fig. 10 gives a curve ${ }^{1}$ showing the variation in candle-power, and the resultant illumination produced. With angles of incidence from $0^{\circ}$ to about $55^{\circ}$, the light is obstructed by the lower carbon, which determines the candle-power. Beyond $55^{\circ}$ the light follows a regular law, but not that of the cosine-cubed, for the light is not emitted from a mass of flame but from a horizontal disk or crater. The projected area of this crater, as seen from any direction, varies as the cosine of the angle. The cosine being introduced for the fourth time, the illumination varies as the fourth power of the cosine. The curve of $\cos ^{4} \theta$ is given in Fig. 10. The total light is $\pi$, and a right-angled cone contains half the whole light.

\section{Street-Lightivg.}

Electric glow-lamps have rarely been used with success for street-lighting up to the present : but too much has been expected from them. Street-lighting differs from almost all other lighting in that the actual illumination produced on the ground is not by any means the only important result; but since this illumination is so marked a feature of a well-lit street, it is often assumed to be the sole object of street-lighting. A very important function of street-lamps is that of beacons to mark out the road. The gas-lit buoys which mark out channels, give no appreciable illumination in the proper sense of the word, and the sense in which it is used. in the present Paper, but they, none the less, serve a most important purpose. Ordinary 5-feet gas-burners in a wide and important street such as Piccadilly, and those in suburban roads, are of little use other than as guides.

Illumination begins to be useful when it is comparable with moonlight. Out of a number of measurements made by the Author at and near full-moon, none have ever reached a higher value than about one-thirty-sixth of a candle-foot; that is, a candle at 6 feet. A bright moon in London, standing high in the sky, is generally between one-sixtieth and one-hundredth of a candle-foot, that is, a candle at 8 to 10 feet. These illuminations were taken on a screen turned full to the moon, and do not include the diffused light from the surrounding sky, which is often considerable, and brings the

1 Derived by Mr. Wybauw from measurements of twenty-six different arclamps by Professor Rousseau at the Antwerp Exhibition, 1885. 
whole illumination up to one-thirtieth of a candle-foot. The moon is not often alluded to in Papers before this Institution, but that it occupies a somewhat important place in engineering, is proved by the custom of dispensing with electric light in many towns in the United States on moonlight nights, and the fact that American Electric Journals give monthly tables of the moon. As much coal is probably saved in the United States in this manner, as might he saved by the use of steam-engines and dynamos of high efficiency.

Moonlight is a useful standard of illumination, but it must be remembered that the perfect uniformity gives it a rather fictitious value, and it is not until an attempt is made to read, say, the time on a watch, that its real feebleness is apparent. A unit of illumination, having perhaps quite as close a connection with the C. G. S. system as has the Parliamentary candle, is that illumination at which it is possible to read Bradshaw's Guide. Moonlight in this country does not come up to this standard.

The varying height of the moon in the sky, and the different illumination which is thereby cast on the ground and on the walls of houses, calls attention to the fact that the illumination on the ground must not be the only consideration of outdoor lighting. For the lighting of docks, wharves, railway goods-yards and other open spaces, the horizontal illumination demands most attention. But it may be suggested that for street-work and the lighting of large interiors, such as railway-stations, the illumination of side-walls is quite as important, and that if any one wishes to consult his watch he will not hold it horizontally, but with the face turned full towards the light. It appears best to aim at a fair illumination of the ground, this being the most difficult. If there are houses near the lamps, so much the better for the general effect, but the lamps should not be spaced further apart for this reason.

\section{General Cases of Distribution.}

The illumination on a surface turned full to the light varies inversely as the square of the distance, and, according to the convention assumed in this Paper, as the square of the cosine of the inclination of the ray with the vertical. The curve of illumination of this character is shown in Fig. 11. The illumination of a vertical plane, the height of which is small compared with the height of the lamp-for example, the side of a truck in a goods-yard lighted by high lamps, is proportional to the product of the sine of the angle into the square of the cosine. The curve of this illumination is given in Fig. 11. It will be noticed that it is zero below the

[THE IXST. C.E. VOL. CX.] 
lamp, and is equal to the illumination on a horizontal plane at $45^{\circ}$, and continually approaches the curve of the squared cosine. The curve of cosines from which all these functions are derived, is also given in Fig. 11, from which the illumination on any surface, and at any reasonable distance from the lamp, can be found. Table $\mathrm{V}$ in the Appendix gives the values of $\theta, \cos \theta, \cos ^{2} \theta, \cos ^{3} \theta$, and $\cos ^{4} \theta$, from which Fig. 11 was plotted. The illumination on the wall of a house facing a lamp, and at a distance measured by the angle of incidence of a ray striking its foot, follows the square of the cosine on that part which is on a level with the light, and falls off to the product of the sine into the square of the cosine at the foot of the wall.

Precisely the same law is followed in the variation of the illumination at a given point, when a lamp in the neighbourhood is placed at different heights in a perpendicular line. This case seems to have been misunderstood by several writers. The curve

Fig. 11 .

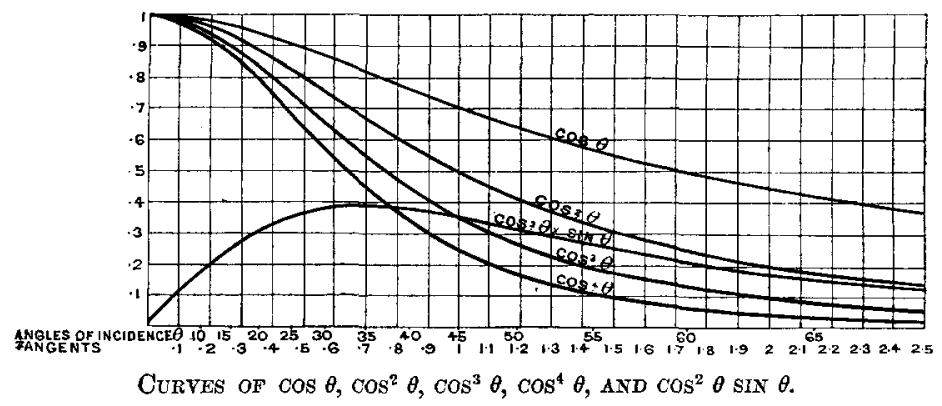

in Fig. 12 represents the illumination produced at the point A by a source of light placed at different heights in the vertical line BC. This curve differs from the preceding ones in this Paper, since the illumination is here measured along the horizontal scale instead of the vertical. The vertical scale in this figure represents the variable height of the source of light; when the light is situated at the point $D$, the illumination at $A$ is a maximum, and it may be shown that $\mathrm{BA}=\mathrm{BD} \times \sqrt{ } 2$, and that the angle of incidence $\mathrm{BDA}$ is $54^{\circ} 44^{\prime}$. It will be observed that a small change in the height $\mathrm{BD}$ may be made without appreciably altering the illumination at $A$. If the height be decreased, the illumination at $A$ will fall off owing to the large angle of incidence. If the height be increased, the illumination will be diminished owing to the increased distance. 
But it cannot be deduced from this that, for ordinary illumination of open spaces, there is any special virtue in the angle of incidence, or that a circle having a radius $\sqrt{2}$, the heights of the lamps being unity, is more "efficiently" lit than any other. The illumination at the circumference of such a circle is very nearly $0 \cdot 2$ of the maximum, which would be found immediately below the lamp, if it emitted light uniformly in all directions. The total light falling within the circle is $0 \cdot 427$ of the whole light falling on the horizontal plane below the lamp. The distribution produced by several lamps in a row, each being supposed to command such a circle, would closely resemble that represented in Fig. 8 ; the usefulness of this arrangement is really limited to the particular case represented in Fig. 12, viz, the maximum illumination of the point $A$ by a lamp situated at any point in the line C B.

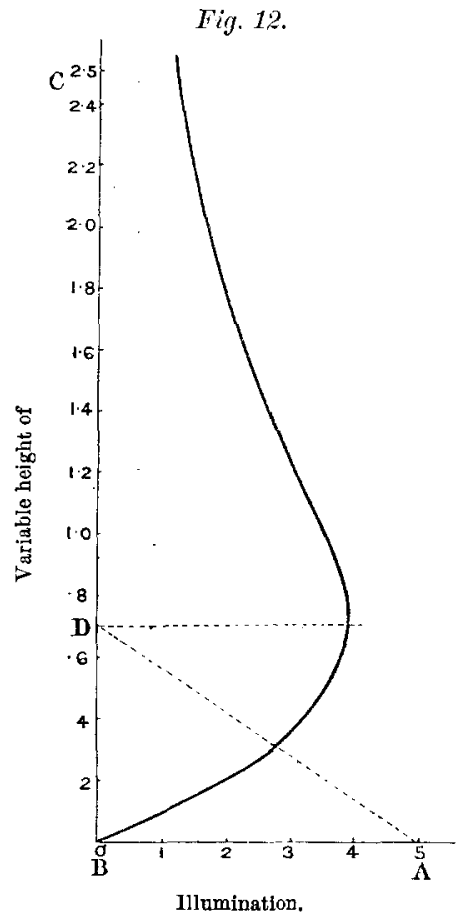

\section{Distribution over a Plane.}

The foregoing considerations relate only to the distribution of illumination along a straight line, and the typical curves in Figs. $6,7,8$, and 9 show the result of different spacings only in the line of the lamps. With the exception of such rare cases as Hyde Park Corner, or the illumination of a very large hall, the arrangement of the lamps almost always consists of rows of lamps set alternately on each side of a street, or a single row down the middle, as on many railway-platforms, and in Tottenham Court Road and Euston Road. With the riew of learning what might be expected in practical lighting, the contour-lines of equal illumination given in Figs. 13, 14, 16, and 18 were calculated and drawn. Fig. 13 represents the contour-lines of equal illumination given by two 
lamps at a distance apart equal to three times their height. If these contour-lines be considered to represent a solid figure, then Fig. 8 represents a vertical section through such a figure in the line A B, with this difference: that Fig. 13 represents the result of two lamps only, while Fig. 8 represents the space between the two middle lamps of a row of four. Full lines are drawn for the contours of $90,80,70,8 \mathrm{c}$, and dotted lines for 45 and 35 , the maximum illumination below the lamp being 100 . The contourlines for lamps at a greater distance apart are very similar to those shown in Fig. 13, and always consist of more or less circular

Fig. 13.

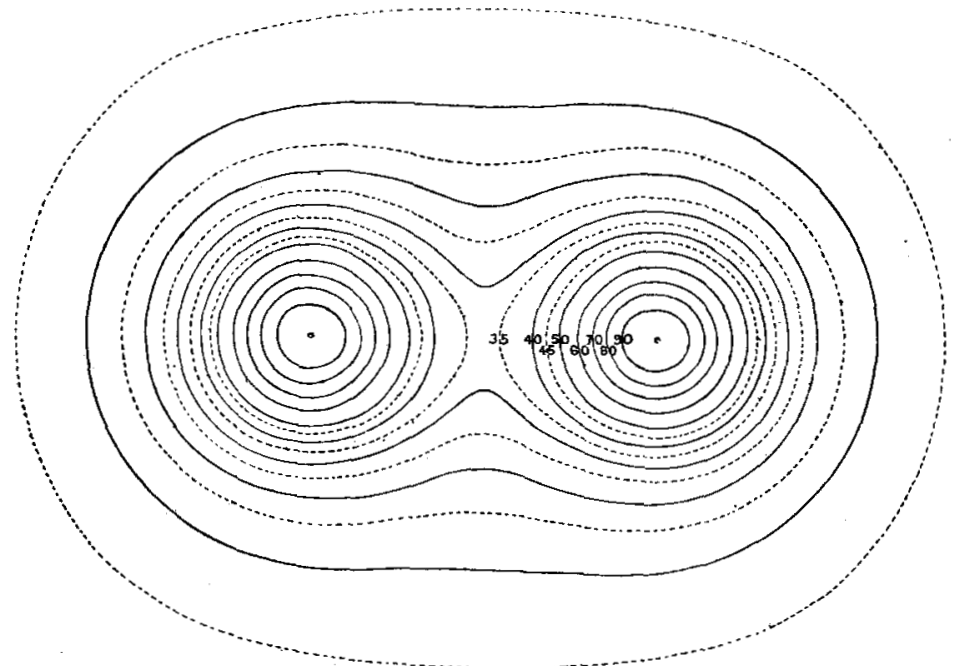

Contour-lines of Equal Illcmination due to Two Lights at a mistance apart equal to Three Times their Hetght.

curves, surrounded by hour-glass shaped curves which pass into more or less elliptical curves. The resultant contour-lines for three lamps placed at the corners of an equilateral triangle, the side of which is 1.5 of the height of the lamp above the ground, are given in Fig. 14. Treating this as a solid figure, Fig. 15, an illumination-curve like Figs. 6 to 9 , may be considered as a section through the line A B of Fig. 14.

It is to be noticed that the points of maxima are not under the lamps; and that within the triangle, the illumination does not vary more than 10 per cent. The contour-lines for three lamps more widely spaced are of the same character, but become less interesting, 
as the more or less circular contours round the lamps become more important; and, in most cases of street-lighting, the other curves are

Fig. 14 .

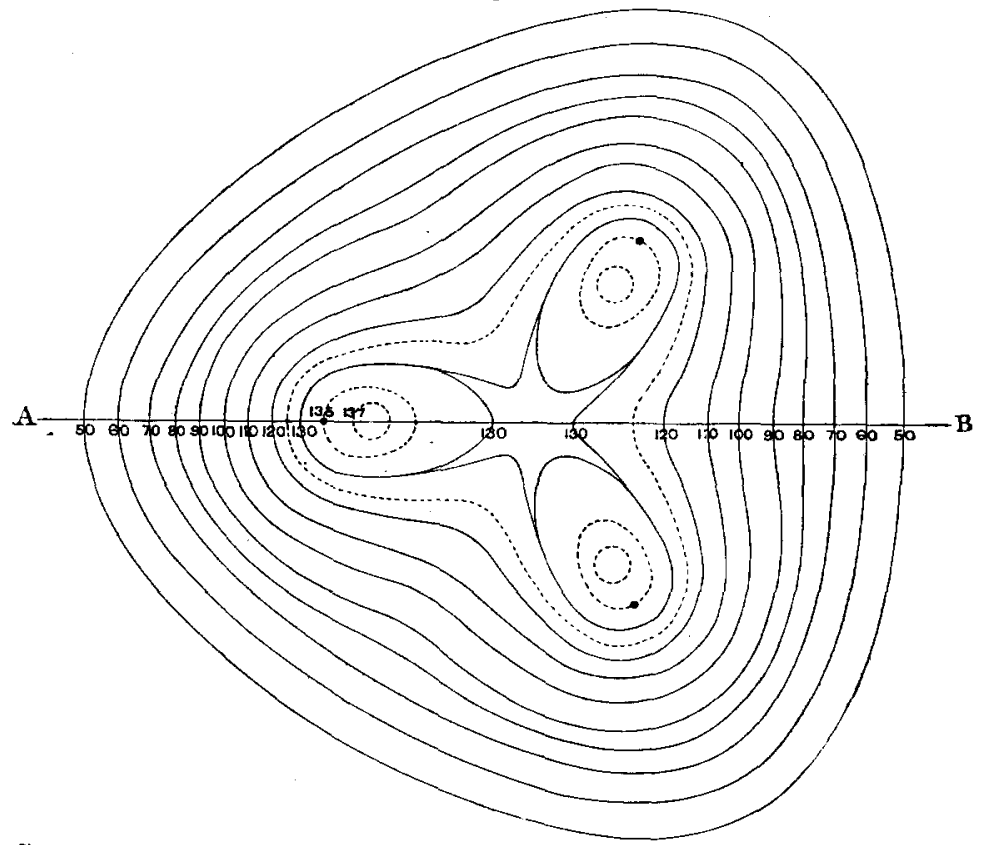

Contock-Lines of Equal Ilfumination due to Three Lamps at distances apart eqLal to One-ANd-A-Haty 'Times thein Height.

Fig. 15.

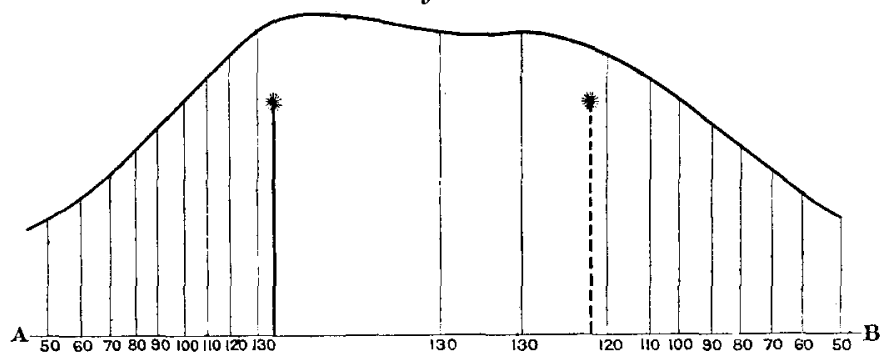

Curve of Illumination due to Three Lamps at distances apart equal to One-and-a-Half Times their Height, being a Segtion of Fig. 14 THROVGH THE LINE A B.

negligible, since they would refer to differences of illumination which are far too small to be of any practical importance. 
With arc-lamps the contour-lines present a very different character, owing to the peculiar distribution of the light. The contour-lines shown in Figs. 16 and 18 have been constructed on

Fig. 16.

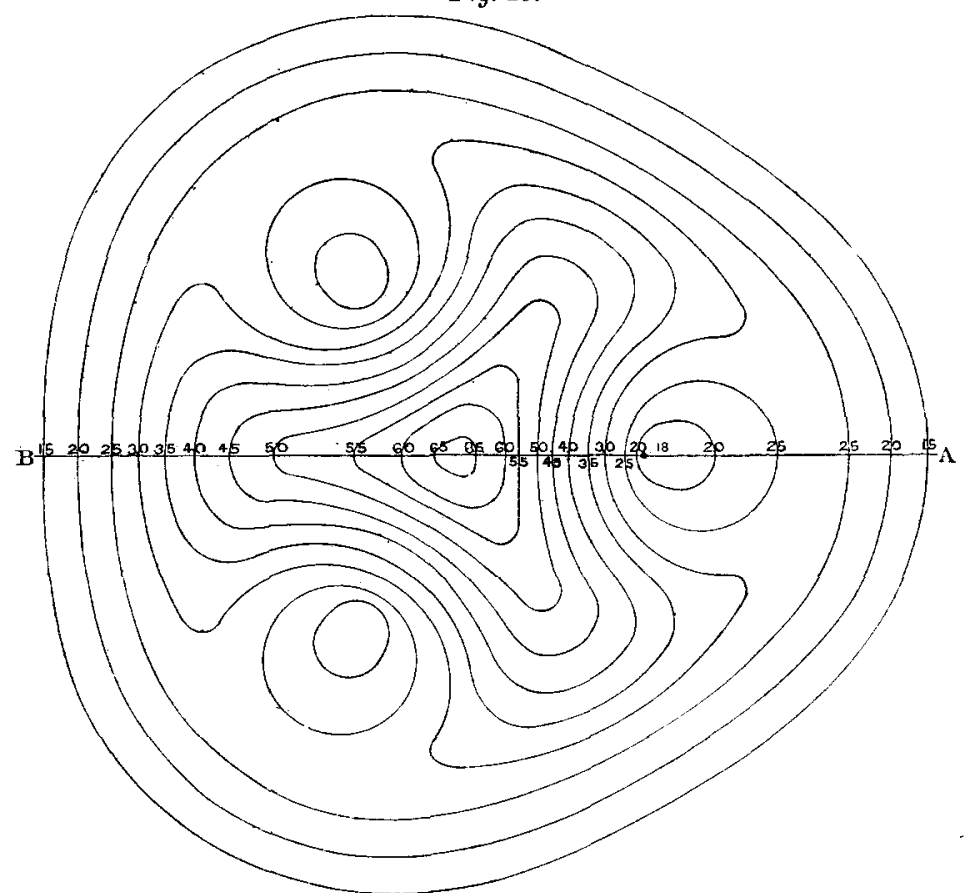

Contovn-I ines of Equal Illumination dee to Three Arc-Lamps at distances apart equal to One-and-a-Half T'imes their Height.

Fig. 17.

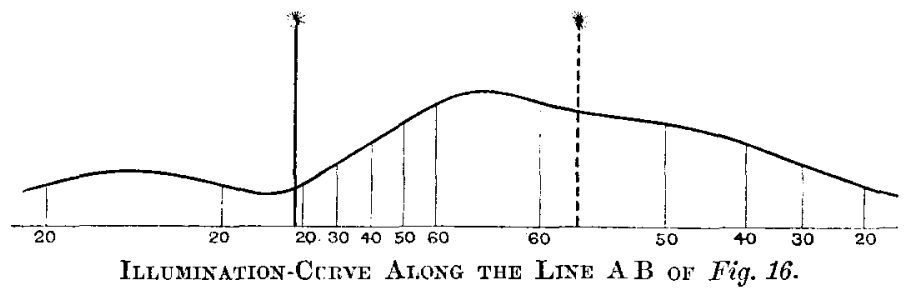

the assumption that the light is distributed according to the eurve obtained by Mr. Wybauw, which is given in Fig. 10. The lines in Fig. 16 represent the distribution of illumination due to three 
arc-lamps at distances apart equal to 1.5 of their height. Fig. 17 represents a section through AB in Fig. 16. Fig. 18 shows the

Fig. 18.

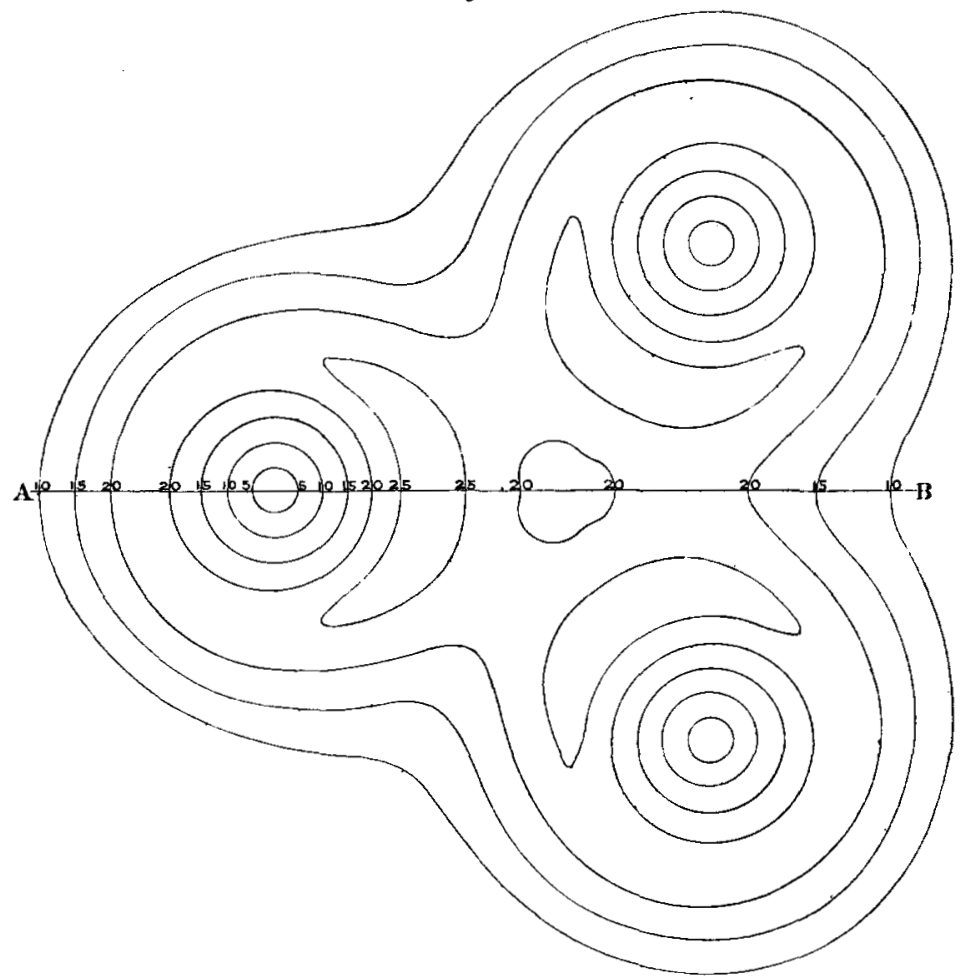

Contour-Lines of Fqual Ilitmination due to Threg Arc-Lamps at distaxces apart equal to Three Times their Height.

Fig. 19 .

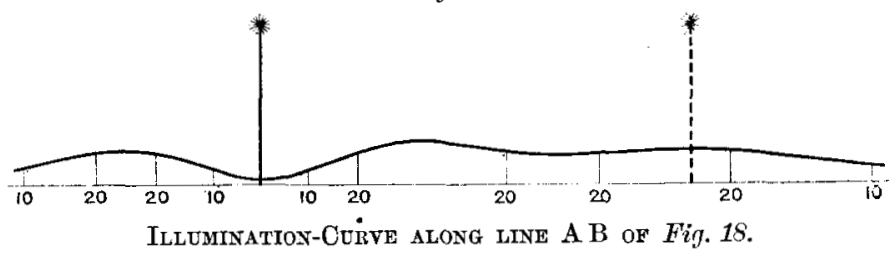

contour-lines for three arc-lamps placed at distances apart equal to three times their height, and Fig. 19 represents a section through 
A B, Fig. 18. The values given for the illumination at each contour are arbitrary, but do not differ much from the values given in Fig. 10. These curves (Figg. 14, 16, and 18) have been constructed by a modification of a method described by M. F. Loppe, (L'Électricien, 1890, vol. xiv. p. 957), but the Author is not aware that any such contour-lines have been published. The sections were deduced from the contours.

Five or six visits were made to Queen Victoria Street, the earlier ones to test the range of the scale, and the mechanical details of the photometer, and two for careful measurements of the illumination of the street. Besides numerous measurements of maxima and minima, readings were taken at about every 10 feet along the zig-zag line joining three lamps. Similar measurements were made in Cornhill, Tottenham Court Road, Euston Road, Whitehall, and Great George Street. The results are given in the third section of the present Paper.

These measurements may be expressed graphically in three different ways. (1) By illumination-curves, like Figs. 6-9; (2) by contour-lines, like Figs. 13, 14, 16, and 18; or (3) by curves which express all the important points or characteristics of any example of illumination. For these, the Author suggests the name characteristic curves.

\section{IlluUMination-Cunves.}

The Author is still rather doubtful as to the best ratio of the vertical scale to the horizontal seale for the illumination-curves. The convention assumed in the earlier part of this Paper, that the height of the lamp and the maximum illumination should both be taken as unity, ceases to be useful when the maximum has an arbitrary or accidental value, as in arc-lighting. At angles of incidence greater than $55^{\circ}$, it has been already shown that the illumination from an are-lamp on a horizontal plane practically varies as the fourth power of the cosine. It is found that the maximum illumination is in practice at about $45^{\circ}$, and, from Table $V$ in the Appendix, it is seen that the fourth power of the cosine of $45^{\circ}$ is $0 \cdot 25$. If, then, the beight of the lamp be set off on the same scale of feet as the horizontal measurements, and if it be assumed that the maximum illumination measured on a vertical scale be represented by a height equal to $0 \cdot 25$ of the height of the lamp, the illumination-curve will correspond, as nearly as is practicable, with the ideal curve given in Fig. 10. The illumination-curve in 
Fig. 31, which will be described later, is arranged thus. On the other hand, the shapes of the curves can be more readily compared, and space may be saved, by making the ordinate representing the maximum illumination equal to the height of the lamp; while the most convenient method is to fit the scale of illumination to any arbitrary number of squares on squared paper, as in Figs. 29, 30, 32, 33, 35, \&c.

\section{Contour-Lines.}

While the illumination-curves give a good idea of the distribution along a given line, they do not express the distribution over the whole area. The contour-lines in most street-work resemble Fig. 13 rather than Fig. 14 ; but it will be seen in Fig. 35, which will be described later, that they practically consist of circles with a fairly uniform space between them. To give an idea of the distribution, the difference between each line should of course be constant. In the present examples they are drawn at every tenth or twentieth of a candle-foot.

With such wide spacing of the lamps, the hour-glass-shaped lines which run in at the minima are beyond the limits of accuracy of the present work, and would be influenced by insignificant flickering, irregularity of glazing of the lamp, and unevenness of the street. It must be confessed that when a fair number of contourlines are given, and all of them are practically circular, the lighting of the street is "spotty."

\section{Characteristic Curves.}

A characteristic curve of illumination is a diagram which resembles a steam-indicator diagram in several respects, since the co-ordinates are the measures of an intensity and of an extension respectively, and the area is the measure of a power. The ordinates show the illumination, and the abscisse the areas. The maximum and minimum illuminations may be seen at a glance, and the shape of the curve shows the quality or regularity of distribution. The departure of the upper line from the horizontal shows the want of uniformity of illumination. The area illuminated to any given degree may be easily found, just as an indicator-diagram shows that portion of the stroke during 
which the steam-pressure exceeds any given amount. The area of the diagram is a measure of the total light, and is really a measure of power in an optical form. Taking the simplest possible case, viz., a single lamp emitting light uniformly in all directions, the illumination-curve being expressed by the full line in Fig. 4, a circle of any given raàius being selected, the character of the illumination may be expressed by plotting areas as abscisse, and the candle-foot to be found on those areas as ordinates. Taking the minimum illumination as 0.1 , the radius may bo found from Table III, as $1 \cdot 907$, the height of the lamp and the maximum illumination being unity. The area of this circle is 11.4 . The curve A B C D, Fig. 20, is cal-

Fig. 20.

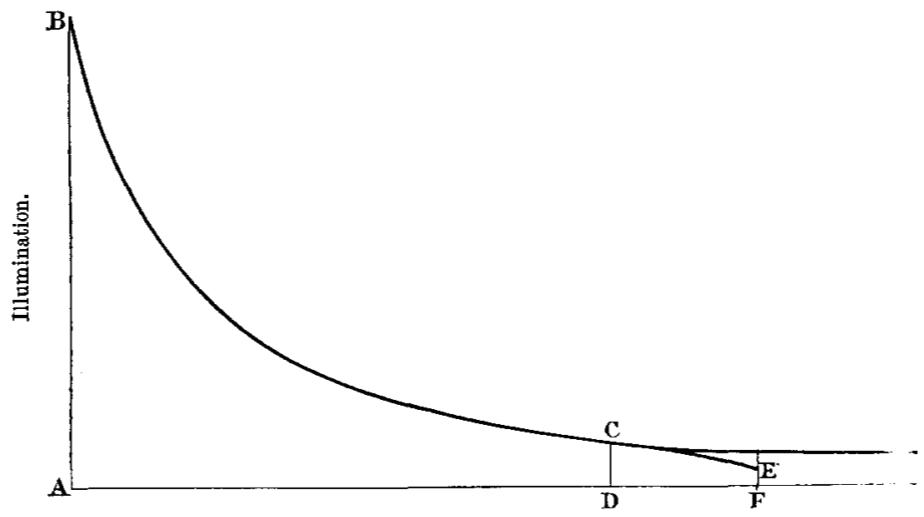

Characteristic Curve for a Circolar, axd for a Square, Area.

culated from Table III, the horizontal measurements being areas. This curve differs from the cosine-cubed curve in Fig. 4 only in the horizontal scale, the former being the square of the latter, but reduced to a convenient length. The early part of the curve becomes as it were shrivelled up, and the flat top seen in Fig. 4 is imperceptible.

If, instead of a circular area, a square one be chosen, the extremity of the characteristic curve becomes modified. Let a square be circumscribed round the circular area, as in Fig. 21. The parts of the square beyond the circle diminish in illumination, but diminish more rapidly in area as their distance from the centre increases. The limiting illumination is found to be $0 \cdot 04$, and the 
remainder of the curve has been calculated, and is represented by $\mathrm{C}$ E in Fig. 20.

Since the characteristic curve may be regarded as a cosine-cubed curve, with a transformed scale of abscissæ, the characteristics of those types of distribution shown in Figs. $6,7,8$, and 9 , may be found. When a characteristic curve is drawn to represent the distribution of illumination of more than one light, the maximum area may be reduced to one hundred; and areas are then represented on a decimally divided horizontal scale, from which percentages may be read off. The characteristic curves given in Fig. 22 are derived from the curves in Figs. 6, 7, 8, and 9, both the maximum illumination and the maximum area being reduced to one hundred.

'I'hese characteristics do not strictly represent the distribution of illumination over a large area illuminated by lamps in rows, since there are several different ways in which such lamps may be arranged, viz., quadrilaterally, as at the corners of squares on a chess-board; quincuncially, as at the centres of squares of one colour on a chess-board; or hexagonally, as the cells of a honeycomb. The variations of illumination represented in Fig. 22 are simply those of the resultant curves in Figs. 6 to 9 , and the areas are supposed to be circular.

The characteristic of $d=3 h$ (that is, distance of lamps equals three times their height), does not present any remarkable features, and as this is practically the same as the illumination produced by a light commanding a circle whose radius is $\sqrt{ } 2$, the height of the lamp being unity, the peculiar efficiency of this arrangement, which has been alleged by some writers, is not apparent.

It has been suggested by Mr. W. H. Y. Webber, ${ }^{1}$ who has commenced a series of articles since the greater part of the present Paper was written, that the practical measure of the efficiency of lighting is given by the difference between the brightest and the dimmest parts of the illuminated area. This difference is represented by the difference between the curves of maxima and minima in Fig. 23. The way in which this difference increases with the wider spacing of the lights is worth noticing, but it conveys no information as to the area illuminated to different degrees.

With the calculated characteristic curves as guides, the charac-

1 Journal of Gas Lighting, rol. lix. p. 197. Feb. 2, 1892. 
teristics of the examples of street-work may be approximately Fig. 22.

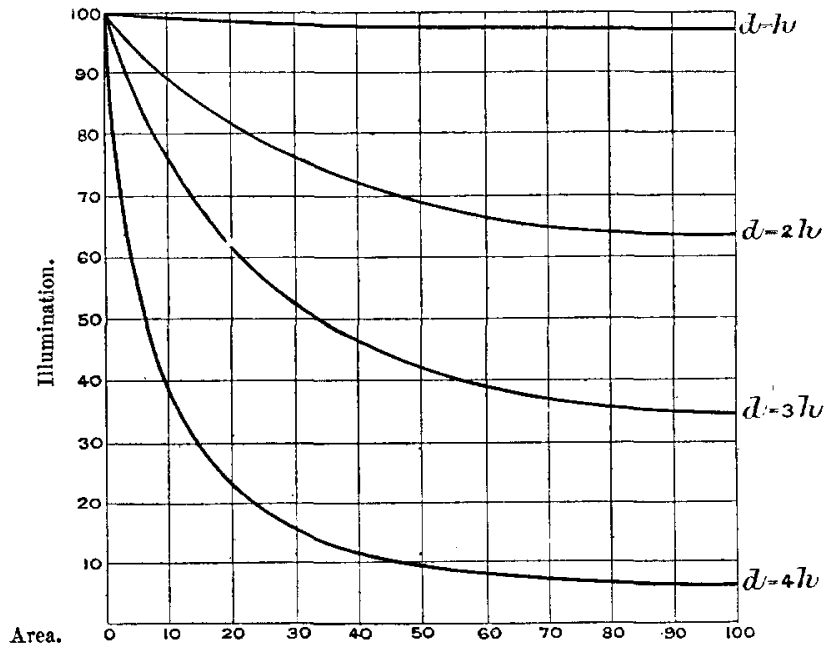

Characteristic Curves for Lamps, at a mistance apart equal to Once, Twice, Three Trmes, and Six Times their Height.

Fig. 23.

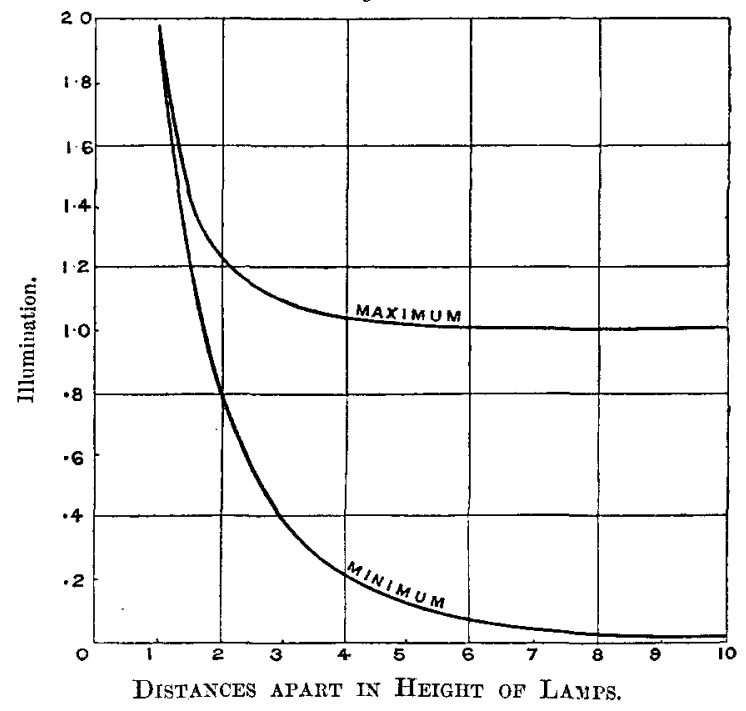

found with very little trouble. The curve for a circular area is 
easily drawn; it is only necessary to take the radius of any given illumination on the illumination-curve which has been plotted from the street-lighting measurements, and to plot that radius against the area of a circle of that radius. Square and triangular areas would be more troublesome, but the lower part of the characteristics for widely-spaced lamps in ordinary street-lighting is very flat, and the last part must be horizontal.

\section{SECTION II.}

\section{Photometrix.}

Photometry, as has already been observed, has hitherto been confined chiefly to scientific laboratory research, and to the commercial testing of gas. The former branch of the subject does not seem to have been very attractive, probably because it is one of the least accurate kinds of measurement. Numerous attempts have been made to banish photometry altogether from the physical laboratory. The radiometer, it was hoped, would supplant it; but the effect of the luminous rays, when separated from the thermal, is very feeble. The thermopile has been used to indicate the whole radiant energy by means of electrical apparatus, and the dark heat rays have been successfully filtered out by selective absorption. Considerable accuracy is possible with the best thermopiles, but the apparatus is unsuited for ordinary engineering work, and great precautions must be taken to avoid any changes of temperature or unsuspected radiation of heat, which would appear in the results as though it were part of the light to be measured. Photometers depending on chemical combinations of gases, \&c., may also be dismissed, as either insufficiently developed or unsuitable for the present purpose. Photographic methods have been suggested; daylight and sunlight have been thus investigated by Sir H. Roscoe and by Mr. W. Brennand, ${ }^{1}$ and the Author has made several attempts, with very encouraging results, to measure illumination in this manner. The "bougie-metre-second" has been adopted by the International Photographic Congress, held at Brussels in the autumn of 1891, and promises to be a very useful quantity. The Author finds that an illumination of 5 candle-footseconds produces a very sensitive shade of grey on the bromide paper known as "Ilford slow." To measure an illumination of

1 Proceedings Royal Society, vol. xlix. Read Dacember 11, 1890. 
about 1 candle-foot, part of a strip of such paper was exposed for five seconds, and the other part was afterwards exposed at home, also for five seconds, to different illuminations, e.g., $0 \cdot 8,0 \cdot 9,1 \cdot 0$, $1 \cdot 1,1 \cdot 2$ candle-foot. The two parts of the strip were developed together in the same dish. This treatment produced a number of bands of different tone, forming a scale; and the tone of the teststrip could be compared with the scale, and its value estimated. The production of a scale by varying the length of exposure is inuch easier; but the relation between the time of exposure and the tone is very complex, and presents many difficulties. The photographic method could be employed for integrating the whole illumination of a street, by carrying about a sensitive strip in a systematic manner all over the district to be measured, occupying, say, half-an-hour for $\frac{1}{4}$ mile of street. The chemical development of a number of test strips can be carried out as rapidly as the calculation of a number of indicator-diagrams, and, like them, is to be valued for the permanent record of the measurements afforded.

By a photometer, a gas-engineer means an assemblage of apparatus of different kinds, including meters, pressure-gauges, thermometers, balance, and other accessories, a remarkable feature of the collection being a great elaboration of cabinet-work and velvet curtains. Photometry in like manner suggests to a gas-engineer the art of manipulating and observing all these instruments, and co-ordinating the results for the purposes for which the tests are made. Lord Kelvin, on the other hand, has asserted that no one can want a better photometer than one composed of a pencil and a card. Dismissing the expensive paraphernalia which are needed, not for real photometry, but for gas-testing, the photometers proper can be divided into three classes:- the Bunsen, the Rumford, and the Foucault. The most common form of the first is a screen of paper with a grease-spot; the second, the one alluded to by Lord Kelvin, a rod, casting two shadows on a screen; and the third, a translucent screen, separated into halves by a partition at right-angles to it. The Bunsen photometer is almost invariably employed for gas-testing; the Rumford, or shadow method, is frequently used in physical laboratories; while the Foucault is a favourite in France, but has been recommended by Mr. Vernon Harcourt for gas-testing. The ordinary gas-testing photometer is used in the large majority of cases, for testing a flame of about 16 candle-power against a standard of 2 candle-power. Small differences are looked for, and a wide range is rarely needed. The dimensions of the apparatus being limited by the cabinet-work and upholstery, and a pair of candles 
being frequently employed as a standard, a shadow-photometer cannot well be used, since the edge of the shadows under these circumstances would not be sufficiently sharp to enable an easy comparison to be made. The popularity of the Bunsen instrument is partly accounted for thus. While the object of this Paper is rather to discuss photometers for measuring illumination, two modifications of the shadow-photometer, devised by the Author in the course of his investigations, may be here described.

A disadvantage of the ordinary rod-and-screen instrument is that, as commonly arranged, a considerable part of the screen, which is useless, is illuminated by the two lights simultaneously, while the shadows which have to be observed receive only half this illumination. The eye is thus dazzled, and there are generally practical difficulties in increasing the width of the shadows. The Author has arranged a strip of looking-glass to cast a shadow from one light on a screen; and has arranged it at an angle of $45^{\circ}$, so that the light from the other source is superposed upon the shadow. Adjustment is made so that one edge of the shadow coincides with one edge of the reflected beam; when a balance is obtained, the whole screen is of the same tone, with the exception of a narrow strip of shadow or added illumination, if the reflected beam is wider or narrower than the shadow.

While testing such a mirror-shadow photometer, with the object of finding the correction to be made for the absorption of the mirror, the Author desired to keep a check on two practically equal lights, and for this purpose arranged an ordinary shadow photometer. It was convenient to place the rod and screen horizontally, and, to bring the two shadows into juxtaposition, the rod was placed nearly in a line with the two lights. With this arrangement, it is clear that the shadow thrown by either light is most intense in the neighbourhood of that light, and falls off at a distance. The intensity of two shadows diminishes in opposite directions, and they match each other in tone at a certain point. If the lights are equal in candle-power, and are symmetrically arranged, the match will be found at the middle point between them. If they are of unequal power, the position of the point at which the two shadows match will be displaced towards the weaker light. A scale can be arranged, by which the relative strength of the lights may be read off by simple inspection. The Author is not aware that any direct-reading photometer has been previously used.

Thet the scale A B, Fig. 24, be 5 feet long, and let the ends bo immediately below the two lights which are fixed at this distance 
apart. Let the illumination due to each light at the middle point on the scale be one-tenth of the maximum illumination at the end of the scale, that is at the point nearest the light. $\operatorname{Cos}^{3} \theta$ then is $0 \cdot 1, \theta$ is $62^{\circ} 20^{\prime}, \tan \theta$ is $1 \cdot 907$. The half-length of the scale is, therefore, $1 \cdot 907$ times the distance of the lamp from the scale. The half-length of the scale being 30 inches, the lamps must be fixed at $15 \cdot 7$ inches from the scale. If $\theta$ and $\phi$ be the angles of incidence at the matching point on the scale, the candle-power of the two lights being $a$ and $b$,

$$
a \cos ^{3} \theta,=b \cos ^{3} \phi
$$

and $\tan \phi+\tan \theta$ is a constant, being the length of the scale. The value of $a$ being unity, that is, the standard of light, $b$ can be found in terms of $\tan \phi$; that is to say, the scale in Fig. 25 may be

Fig. 24.

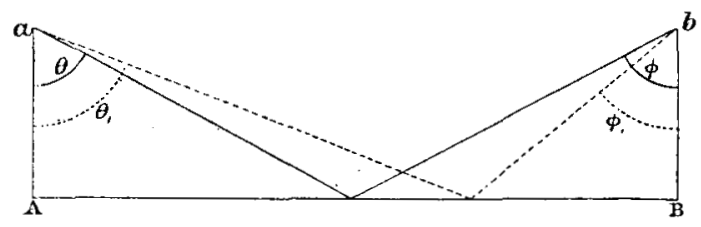

Fig. 25 .

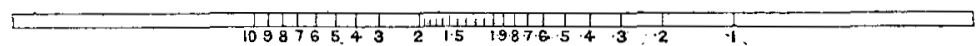

Scale of Direct-Reading Photoneter.

graduated in candle-power in terms of a. As horizontal measurements are generally taken, and as the light emitted by many lamps and flames differs at different angles, this form of photometer would be more useful if the scale were arranged vertically, and in the horizontal plane of the lights to be compared. It is not easy to read off the position at which the two shadows match, but the Author believes that, with a little practice and a choice of the best ratio of the length of scale to the distance of the lamps from it, very quick readings could be taken, and that this photometer may be useful to makers of glow-lamps. It is essential that the scale be perfectly flat.

\section{Illumination-Photoueters.}

The first photometer that appears to have been designed and employed for measuring illumination was that of Professor Weber. A standard lamp is arranged in a box at one end of a horizontal 
tube. In this tube, and capable of sliding in it, is a transhucent screen of opal, or ground glass. A reflecting prism throws the light down a vertical cross-tube, and by another reflecting prism into an eye-piece. At the top of the vertical tube is a similar piece of translucent glass, and these two screens are observed together. The screen in the horizontal tube is moved until a balance is obtained, when the two screens appear to be equally bright. By a suitable scale the illumination is! read off. This instrument does not appear to give a wide range, and the horizontal tube would have to be very long for measuring feeble illuminations. In a later pattern this defect is reduced by the introduction of a polariscopic arrangement, in which the light is extinguished by the rotation of Nicol prisms. It does not allow measurements to be made near the ground, and, as it would be difficult to arrange a standard height for such measurements, it seems desirable that, for purposes of comparison of street-lighting, the illumination on the ground or a few inches above it should be considered.

Another somewhat similar instrument has been devised by Professor Mascart, and has been used by him in numerous photometric tests of illumination in Paris. He, like Professor Weber, employed a modification of the Foucault photometer, 'but experienced great difficulty in finding a screen which would transmit light in proportion to the cosine of the angle of incidence. With homogeneous paper, the transmitted light diminished more rapidly than the cosine, and less rapidly than the squared cosine. He ultimately used the kind of screen employed by Foucault, which consists of two sheets of glass, separated by a layer of starch. ${ }^{1}$

Portable photometers, and a street-photometer on wheels, had been used for measuring candle-power; but little attention was paid to the measurement of illumination until Mr. Preece described his illumination-photometer before the Royal Society, on the 21 st of June, 1883. This is also an arrangement of a Bunsen screen. A small glow-lamp, Fig. 26, is fixed in a box, carefully blackened in the interior. Over the end is stretched a Bunsen screen of paper, on the middle of which is a grease-spot. At about 12 inches from the latter is another screen on which drawing-paper is fixed. The grease-spot is so screened that no light falls upon it beyond what is reflected from the screen. At the end of the box opposite the Bunsen screen is an eye-piece, consisting of a plain tube. To make an observation, it is only necessary to place the

1 Société des Électriciens, vol. v. p. 103.

[THE INST. C.E. YOL. CX.] 
instrument so that the reflecting screen receives the illumination which it is desired to measure, and to alter the electric current of the glow-lamp by means of an adjustable resistance, or a rheostat, until the grease-spot becomes invisible. Mr. Preece found by experiments that the candle-power of the glow-lamp increased as the sixth power of the current. The current in amperes thus gave, for a particular lamp, a constant whose sixth power expressed the illumination measured. Professor Kittler, of Darmstadt, and Captain Abney independently corroborated this function, and recent observations ${ }^{1}$ show that, in modern glow-lamps of 8 candlepower, the candle-power varies as the current raised to powers of

Fig. 26.

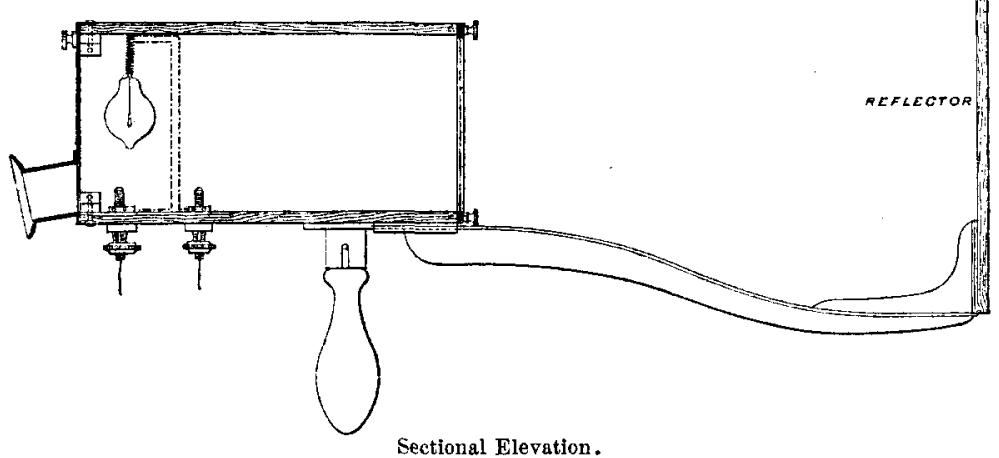

Preece Photometer.

from $5 \cdot 3$ to $6 \cdot 9$. By the use of a reflecting screen, Mr. Preece avoids the difficulty met by Professor Mascart; but, for feeble illuminations, a serious loss of the dim light to be measured is entailed. Having had the opportunity of making a considerable number of measurements with Mr. Preece's 1883 photometer, the Author ventures to comment upon some of its details, and to point out modifications which he has made in adapting it for street-photometry. The instability of a glow-lamp, as a standard, was alluded to by Mr. Preece in his original Paper, but no sudden change is likely to take place in the course of an evening's work. All such secondary standards should be calibrated immediately

1 Technology Quarterly, American Academy of Sciences. Reprinted in The Electrician, vol. xxviii. p. 112. Also a Report on Tests of Lamps, published in The Electrician, July 15th, 1892. 
before and after a series of observations. Sensitive ammeters had not been constructed in 1883, and a differential-galvanometer method was employed for measuring the current. The manufacture of both primary and secondary batteries has made such important strides since that date, that it is no longer necessary to encumber the observer with ammeter or galvanometer. A portable secondary battery, worked at about one-third of its nominal output, may be relied upon for an evening's work, especially if the current be used only during an actual measurement. With such a photometer, the rheostat may be calibrated directly in luces, or candle-feet. A most important field for illumination-photometry exists in arc-lighting, the greatly-debated question of the usefulness and quality of arc-lighting must be reduced to measurement before any practical discussion can take place upon it. Although it is possible to use a glow-lamp for about an hour, with so large a current that the light emitted by it is nearly identical with that of an arc, it is obvious that, when a rheostat is used for diminishing the light, the colour becomes more yellow, and finally, in the measurement of feeble illuminations, becomes orange and dull red. It is by no means impossible to compare the illumination produced by lights of very different colour with a high degree of accuracy, but considerable practice is necessary. Captain Abney and General Festing can estimate the comparative luminosity of a patch of scarlet and a patch of green, brown, or any other colour. The feat seems impossible, and the accuracy, within 2 per cent., incredible to any one who has been inconvenienced by the difficulty of balancing the colour of a candle-flame against the light of an arclamp. The secret of Captain Abney's success is his method of rapidly varying one or both lights, making many and quick changes on each side of the real balance, by the oscillation of a light and easily-moved lever. After very little practice, it is not difficult to make the two lights vary alternately by equal amounts and to decrease this variation until it is hardly sensible. The muscular sense of moving the lever enables its mean position to be found, or the alternate motion may be continued for a couple of seconds, while the observer looks at the scale and estimates the middle position. It does not follow that when the balance is obtained by this method, the two illuminations appear identical to the eye, and it is only by making rapid oscillations on each side of the mean position that the true reading can be discovered. This kind of observation is uncommon in physical measurements, and the accuracy which may be obtained by it will hardly be believed without practical experience. 
The rheostat used in connection with the Preece photometer was an ordinary plug resistance box, one of the rnost difficult pieces of apparatus to use quickly, and quite unsuitable for the method of rapid and gradually diminishing variations. A sliding resistance consisting of a single straight wire might be used, and the Author has tried a resistance composed of 150 turns of No. 30 tinned-iron wire, on a rod 1 foot 6 inches long. Quick and accurate readings could be obtained thus, but the colour difficulty is a serious objection, and one which can be avoided by other means.

Unlike other Bunsen photometers, the Preece photometer employed one side of the screen only, and the observer looked directly at the grease-spot. The theory of the Bunsen photometer shows that a balance can only be a measure of the equality of the illuminations, when the screen is perfectly opaque, and the spot perfectly transparent. Again, the screen of drawing-paper subtends a certain solid angle to the Bunsen spot and this angle is arbitrarily fixed. The readings on this photometer, though fairly accurate, as proved by experiment, depend on the combined result of several different and arbitrary factors.

A modification was designed by the Author in conjunction with Mr. Preece in April 1884, with the view of obviating the colour difficulty and the liability of error produced by different kinds of Bunsen screens. The usual arrangement of screen with two mirrors was employed, allowing both sides of the spot to be seen simultaneously. Upon a tripod, a cylindrical case, Fig. 27, is covered at the top by a horizontal Bunsen screen, and two observingmirrors are inclined at a suitable angle. A glow-lamp slides on a vertical rod, and connection with external terminals is maintained by coiled wires. The lamp is moved by a lever which pushes it in opposition to a spring. The lever is pressed against the cam, and bears against the roller. This roller is mounted on a nut which traverses a vertical screw. Its position may be read on a scale. At the lower end of the screw is a handle and a graduated wheel. The cam is shaped to such a curve that when the nut moves through any given distance, the displacement of the lamp is as the square of that distance; the light of the lamp being adjusted to any required power, balances a given illumination when the scale reads the unit. A balance being effected for any other illumination, its value in terms of the said unit may be read off on the scale. It is not necessary to measure the distance of the filament of the lamp from the screen. This instrument is easy to use, but the range is only from one to ten, and cannot easily be increased. A sliding rheostat and an ammeter were used 
for maintaining at a fixed value the current required to balance the unit illumination.

In recommencing the study of illumination photometry, after an interval of nearly eight years, the Author took up the photometer in a somewhat modified form. He wished to make the measurements as near the ground as possible, and therefore, avoiding the tripod, he arranged a Bunsen screen 6 inches from the ground. To see both sides simultaneously would need three mirrors, and would necessitate a very limited view. As it is very much easier to make observations without an eye-piece, using both eyes, he decided to return to the observation of one side of the Bunsen screen only, and to make an empirical correction if necessary. A 6-inch cube, covered by a Bunsen screen at the top, and open at the side, was used. Some of the unsuccessful

Figs. 27.
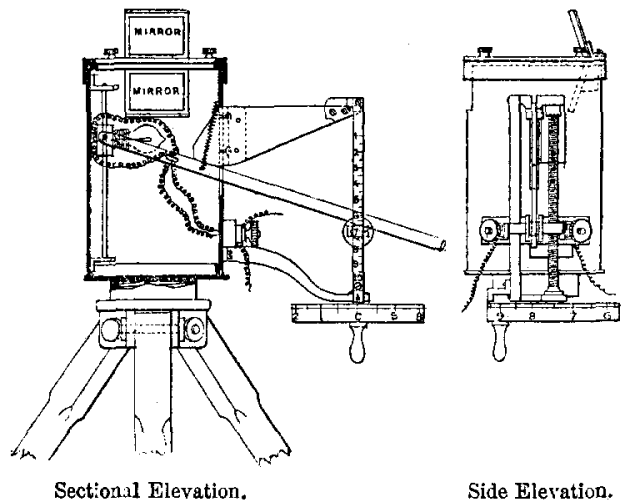

Preece and Trotter Photometer.

attempts will be briefly described, for the purpose of saving the time of other experimenters. A piece of plate looking-glass was fixed at an angle of $45^{\circ}$, and a 1-candle electric-lamp, operated by a secondary battery, was arranged to illuminate it. It was at once found that no balance could be obtained when the screen was viewed from a point directly above it, without a very great disproportion between the illumination of the two sides of the Bunsen screen. It is usual to observe a Bunsen spot from a direction inclined at a small angle to the surface of the screen, and to compare the appearance of the two sides. Owing to the imperfect translucency of the spot, and the often imperfect opacity of the rest of the screen, a complete disappearance is not obtained, even 
when a balance is effected. Again, if the illumination on one side is adjusted so that a complete disappearance of the spot is obtained, when viewed from a certain direction, the spot will reappear if this direction is changed. It is necessary, therefore, in using a photometer which makes use of one side of the screen only, to fix upon a definite direction from which it is to be viewed. As eyepieces are highly objectionable where accurate discrimination of delicate differences of tone are desired, the perpendicular direction of view is almost essential in this form of photometer. A groundglass screen in front of, and immediately in contact with, the mirror, was tried. This was found unsatisfactory, but the instrument at once assumed a practical form when the mirror was replaced by a piece of white paper. In all subsequent work white Bristol board has been used, and this part of the photometer will be called the reflecting screen.

Numerous experiments were made with different kinds of Bunsen spots. The perpendicular direction of view modifies the behaviour of such spots very materially. Tracing-paper stretched over Bristol board, in which a star-shaped hole has been cut, was found to be far superior to any grease-spot, and the two sheets of thin paper used in the " Leeson" disk were unnecessary, since only one side of the screen was used. The best kind of tracing-paper is that which, while having as little colour of its own as possible, is darkest when laid on a black surface. This was used in the earlier work. Tracing-paper with a milky or opaline body does not give so sensitive a spot. For practical use, especially in streetwork, the Bristol board should be mounted on glass, and the tracing-paper, tightly strained, should be pasted over it, taking care not to press it into contact with the glass. The under surface of the glass was blackened, leaving $\frac{1}{16}$ inch round the star.

Further experiments, with the view of finding the most sensitive kind of Bunsen spot, suggested the use of ground glass instead of tracing-paper, and consideration of the fineness of the ground surface suggested the trial of clear glass, or of a simple cardboard screen, with a star-shaped hole cut in it. This was found to be far more sensitive than any other arrangement, and was used in all the later work. The difference in the colours of the standard lamp and of the light to be measured, is more marked than with Bunsen screen with traoing-paper, but the great sensitiveness more than compensates for the disadvantage. It is evident that in an ordinary greased-paper disk, or with a Leeson disk, the two sides of the opaque part are illuminated by the two coloured lights, while the grease-spot acquires an intermediate 
colour, owing to the mingling of the two lights. With a perforated. screen photometer, the reflecting screen is illuminated by the standard lamp, and is seen through the perforation in the horizontal disk. The Author has found little difficulty in matching the illumination from an arc-lamp, even when the standard lamp gave a light of about the same colour as that of a candle. He finds that greater accuracy is possible between 0.6 candle-foot and 0.2 candle-foot than with higher or lower illuminations. The Joly paraffin-block photometer has been tried, but the Author does not find it to be sufficiently sensitive for illuminations of less than 0.5 candle-foot.

The electric lamp was mounted in a box, so that it stood 5 inches above the ground. The object of raising it above the level of the middle of the reflecting screen was to prevent any light from falling directly on the underside of the Bunsen screen, and many erroneous measurements were made before this precaution was taken. Telescopic tubes were used to shut out stray light from the reflecting screen; these tubes, when fully extended, measured 1 foot 4 inches in length. The storage-battery consisted of four Lithanode cells, manufactured by the Mining and General Electric-Lamp Company. Two of these are quite capable of running a $\frac{3}{4}$-candle lamp, at a fair brightness, for ten hours; but in order to allow a good margin, two more cells were connected in parallel. These have proved to be sufficient for the purpose, and no appreciable change in candle-power has been observed between the preliminary calibration and the one which followed each evening's work. A slightly higher power is given immediately after charging, but a quarterof-an-hour's continuous discharge seems to bring the batteries into a very steady condition. The lamp was lighted for as short periods as possible, about ten seconds being sufficient for each reading.

To calibrate this photometer, it was laid on its side, the Bunsen screen being vertical and facing a lamp. Small paraffin-lamps, turned down to give about 1 candle-power, were generally used for this purpose, no measurements being made until they had burned for half-an-hour. The distance from the Bunsen screen to one lamp, when a balance had been obtained, was easily measured, but it was not evident from what point on the reflecting screen the distance of the other lamp should be taken. A point was taken at random, viz., the extreme back of the cube. The lamps were placed at different distances along lines laid down at rightangles, the extreme positions giving an illumination at the photometer of about 0.003 candle-foot, that is, a candle at 18 feet. 
The distances were plotted as rectangular co-ordinates. The points fell for the most part closely on a straight line, showing that the photometer followed the usual law of the squares of the distances. They curved off a little near the origin, as if the lamp which illuminated the reflecting screen increased in candle-power for very short distances; this was probably due to the larger solid angle of light falling on the reflecting screen, and to internal reflection from the back of the Bunsen screen. But the straight line cut the axis at a point 5 inches from the origin. A point 5 inches from the back of the cube was therefore the proper point from which measurements should be taken, in order that the law of the squares of the distance might be followed with fair approximation. Measurements were made with this photometer in several parts of London.

As a typical example of an old-fashioned gas-lit street, one which is undoubtedly known to all members of the Institution of Civil Engineers, Great George Street, Westminster, was the scene of the first street-lighting measurements, and the first observation was made 2 feet from the curb, immediately opposite the entrance to the Institution. The illumination was found to be 0.03 candle-foot. This was read off on a measuring tape graduated directly in candle-feet, the divisions being the reciprocals of the square of the length in feet. For feeble illuminations, it was found that stray light, especially from distant lamps, fell on the reflecting screen, and caused the readings to be too low in spite of the telescopic tubes which were used. Illuminations of 0.005 candle-foot are not uncommon in gas-lit streets. This corresponds to a candle at about 14 feet 2 inches. In streets lighted by arcs, a minimum of 0.025 is frequently found; this corresponds to a candle at 6 feet 4 inches. A complete tube connecting the lamp with the photometer, is therefore practically out of the question, and the Author proceeded to experiment on different methods of diminishing the light.

It is convenient, especially for feeble illumination, to have the Bunsen screen at least $3 \frac{1}{2}$ inches square, and the star-shaped hole or grease-spot should not be less than $1 \frac{1}{4}$ inch across. Many experiments were made with lenses, both concave and convex, but it was found that a range of movement of at least 2 feet 6 inches was necessary, and it was difficult even then to get a uniform illumination on the reflecting screen. The eclipsing device used in dissolving views, required fully 2 feet. Photographically-shaded glass screens were tried, also a pair of lenses sliding over each other, as in a heliometer. The latter device would 
have succeeded, but in low illuminations an image of the lenses appeared. The Author finally adopted the method of inclining the reflecting screen at different angles. As at first arranged, the screen was mounted symmetrically on a horizontal axis, and a pointer was geared to the axis in the ratio of 1 to 12 . The readings for low illuminations were too close together, and, owing to the reflection from the interior of the box, total darkness could not be obtained, even when the lower surface of the Bunsen screen and all the internal parts were carefully blackened. The reflecting screen was then mounted on an axis passing through its upper edge, and was arranged so that it could fold up quite out of the beam. In order that a convenient scale might bo provided, motion

Figs. 23.

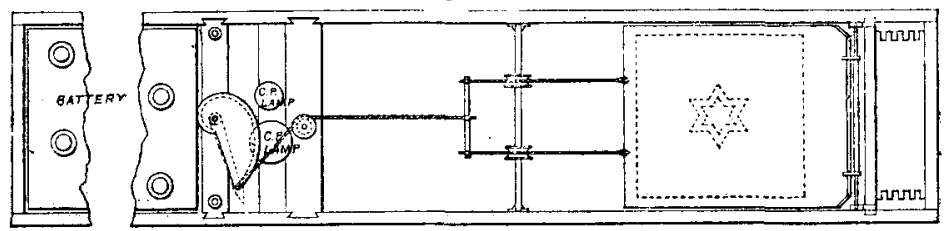

Plan with cover removed.

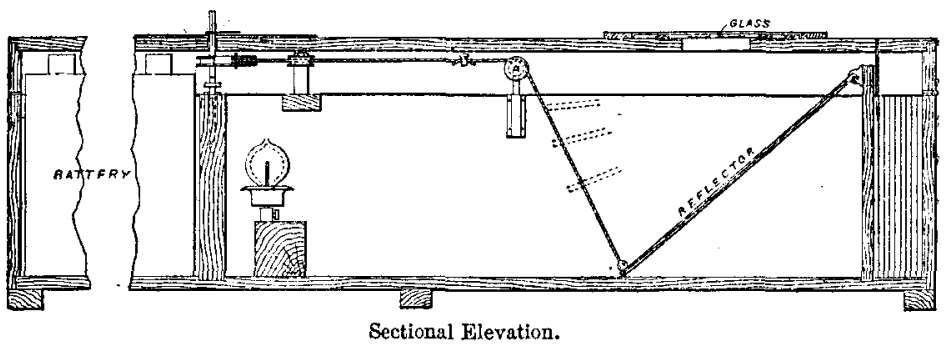

Trotter Photometer.

was given to the reflecting screen by a fine chain wound upon a snail-cam. The cam was designed upon the assumption that the illumination on the screen would be proportional to the cosine of the angle of incidence of the light upon it. This is not strictly the case, especially as a convex lens was used in many of the tests to increase the available light from the electric-lamp. The object of the snail-cam was merely to spread the divisions of the scale more evenly, and did not aim at uniform division. The scale was empirically calibrated with a standard candle. This photometer (Fig. 28) was constructed by the Author. Various alterations were afterwards made by the Mining and General ElectricLamp Co., and by Messrs. Swinburne \& Co. 


\section{SECTION III.}

\section{Results of Measurements.}

The principal object of the measurements of illumination which have been made by the Author and his assistants during the past winter, has been to ascertain the nature of the distribution of light in various streets and public places; a second object was to find the amount of illumination in candle-feet for such places; and the last and least important, from the present point of view, was to deduce the candle-power of the lights which produced that illumination, since that is a matter of ordinary photometry.

While the observed distribution of illumination was found to agree very closely with the general results which might have been arrived at by calculation, the real point of importance for the engineer who has to carry out the lighting of a given street or building to know is, what degree of uniformity is desirable for a particular case; how that degree may be attained by the proper planting of lamp-posts; and the selection of the proper height of such posts. This question of distribution being settled, the amount of illumination becomes a simple question of candle-power. No definite rules can be given as to these matters, and whether this or that street is well or sufficiently lighted, must remain largely a matter of opinion. It seems that 0.03 candle-foot is the lowest point that should be reached in a well-lighted street.

The degree of uniformity, and the amount of illumination in candle-feet may be found by actual measurement, and may be expressed in figures; but the mode of lighting, the arrangement of the lamps, and their height above the ground, while influencing these results, have a very important bearing upon the comfort and usefulness of the general effect.

The lighting of interiors is yet more difficult to describe in general terms, and the Author has made no attempt to reduce it to candles per cubic foot of space, as has been done by Professor Mascart ${ }^{1}$ and Mr. Fontaine, but he will confine himself to the records of observed illumination in a few typical cases.

1 Bulletin de Ia Société Internationale des Électriciens, vol. v. p. 102. 


\section{South Kensington Museum.}

One of the first examples of lighting which was examined by the Author was that of South Kensington Museum, by permission of General Festing. The Sculpture Court, containing the Trajan Column, is well and sufficiently lighted by Brush arc-lamps placed at the very considerable height of about 50 feet. This court is 135 feet by 60 feet, the height to the ceiling is 83 feet. The illumination is quite sufficient for the artists who are to be found there in the evening, sketching architectural and other details. The great size of many of the objects exhibited in this court, prevents more than seven or eight lamps being seen from any one position. It was found that the illumination on the ground at any point depended simply on the number of arc-lamps in sight at that point. The following readings were taken with the 6 -inch cube photometer :-

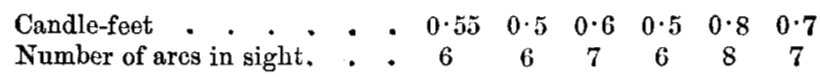

In the Silversmiths' Court the illumination was found to be $2 \cdot 6$ candle-feet, with ten arc-lamps in sight; in the Japanese Court 1. 6 candle-foot, with eight lamps in sight; in the Great Hall, near the centre, 2.4 candle-feet, with nine lamps in sight, the lamps being about 25 feet from the floor. In the gallery over the Silversmiths' Court, near the bookbinding cases, about 3.5 candle-feet were recorded. Opposite the refreshment-room, in the corridor lighted by glow lamps, the illumination was found to be 0.65 candle-foot. A very easy way of counting the number of lamps which can be seen by an eye placed at the photometer-spot, is to hold a pencil upright on the screen; this casts a number of shadows radially, and these may be counted. ${ }^{1}$

1 In the Report on the Action of Light on Water-colours (published as a Blue Book (C. 5453), 1888, by Dr. Russell and Captain Abney), measurements made by General Festing with the Preece photometer are given. North-east water-colour gallery (gas), 1.81 candle-foot; south-east water-colour gallery (gas), 2·32 candle-feet; Jones Bequest gallery (electric glow-lamp), $1 \cdot 72$ candlefoot; Raphael gallery (arc), $2 \cdot 26$ candle-feet; Sheepshanks gallery (arc), 3.12 candle-feet.

The mean natural illumination of daylight measured for the blue rays in one of the galleries during April and May was about 13 candle-feet. On thirteen days it exceeded 20 candle-feet; the maximum was about 36 . 


\section{Charing Cross and Cannon Street Stations.}

By permission of Sir Myles Fenton, measurements were made at Charing Cross and Cannon Street Stations. The arc-lamps at Charing Cross are about 18 feet from the platform. The maximum illumination on the evening of January 29, 1892, was to be found between 15 and 22 feet from the point below the lamp, and varied from 0.4 to 0.5 candle-foot. The minimum was about 0.05 candlefoot. There are fourteen arc-lamps in the station, arranged somewhat irregularly in four rows. The station covers about 9,050 square yards. There are, therefore, roughly, 646 square yards to each lamp.

Two sets of measurements were made at Cannon Street Station,

Fig. 29.

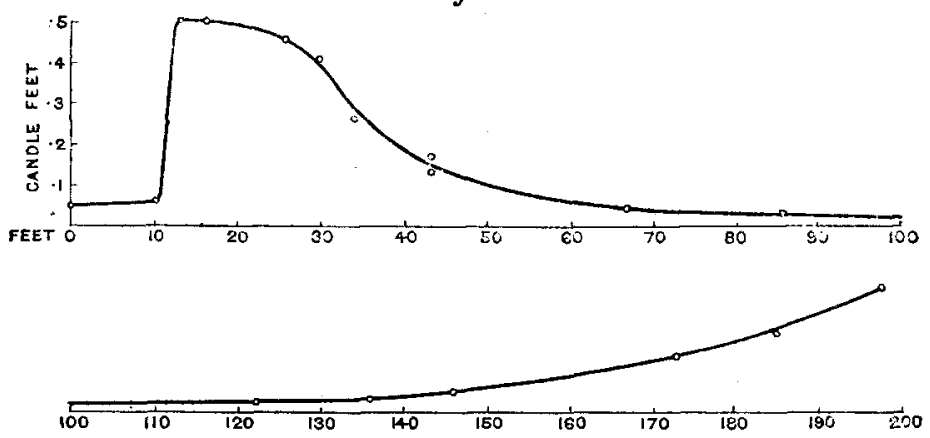

Illumination-Curve along Main-Line Arrival-Platforar, Cantox Street Station.

one with the 6 -inch cube photometer, and another, on the date already mentioned, with the improved form. These measurements agreed fairly well with each other; the first pattern gave low readings for low illuminations, owing to diffused light on the reflecting screen. Fig. 29 shows the distribution of illumination along the main-line arrival-platform, starting from the point beneath a lamp enclosed in a lantern of clear glass. There is a deep shadow of 0.05 to 0.06 candle-foot beneath the lamp; the edge of this shadow is probably sharper than is represented by the curve. All the readings are given as small circles on the curve. The lamps are an old form of the Brockie pattern, and take 15 amperes; they are hung at about 35 feet from the platform. There are eight lamps, arranged symmetrically. The station 
covers about 13,900 square yards, giving about 1,740 square yards to each lamp. The minimum is about 0.025 , and maximum 0.35 , to 0.4 candle-foot, distinctly less than at Charing Cross; but the greater height of the lamps prevents the glare which is to be found at the latter station. Assuming the volts of the lamps to be about the same, the watts expended at Charing Cross are about 15 per cent. greater than at Cannon Street. The difference in illumination is greater than this; but, owing to the irregular arrangement of the lamps at Charing Cross, an exact comparison could not be effected unless a complete survey of the station were made.

\section{City of London.}

The street-lighting in the City has been measured by the Author on several occasions. A very large number of repeated observations would be necessary to give an exact result, since there is a considerable variation of light when the arc-lamps "feed." Figs. 30 and 32 give illumination-curves of different lamps at different times. The three curves A, B, and $\mathrm{C}$ (Fig. 30), are picked from a number, as the best performances of the lamps. In these curves all the readings in any one set of observations are recorded. None have been suppressed as doubtful. The curves are drawn to represent the probable distribution of illumination as nearly as possible. The horizontal distances are given in feet, and an arbitrary scale of candle-feet has been used; that is to say, it has no relation to the height of the lamp, as in the first section of the present Paper. In several of the highest cases it was noticed that the light was not thrown uniformly, owing to the formation of the crater on one side, perhaps on account of bad setting of the carbons.

Fig. 33 gives the illumination-curve of a lamp in Cornhill, measured along the diagonal line in the direction of another lamp. A considerable crowd had collected when seven readings had been taken, and it is assumed that the remainder of the curve would be symmetrical, as shown. Fig. 31 is the curve C (Fig. 30) on another scale. The maximum light being given at about $45^{\circ}$, and $\cos ^{4} 45^{\circ}$ being $0 \cdot 25$, the value of the illumination at the maximum is to be found on the scale of candle-feet, at a height equal to 0.25 of the height of the lamp, this height being moasured in feet on the same scale as that of the horizontal distance. The curve is, however, so flat and uninteresting that the Author only gives it as an example.

In the course of a very careful measurement of the lighting in 
Queen Victoria Street, on the 29th of January, 1892, it happened that the light of the three lamps was, during the greater part of

Figs. 30 .
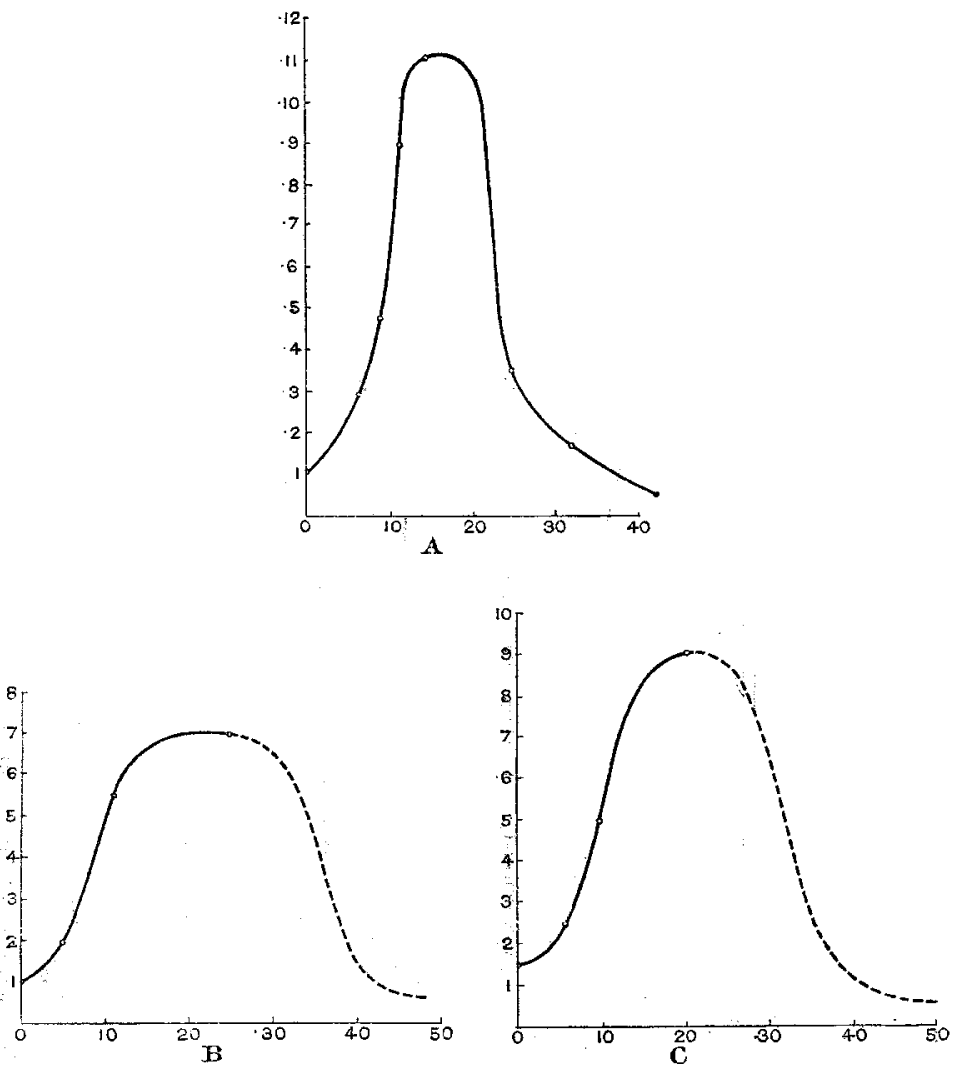

Illumination-Curves of Arc-Lamps in the City.

A. Lamp opposite Brush Electrical Engineering Corporation's Show Rooms. Chequered glass.

B. Lamp near the General Electric Supply Company's offices. Figured glass.

C. Lamp with chequered or square moulded pattern on the glass.

Fig. 31 .

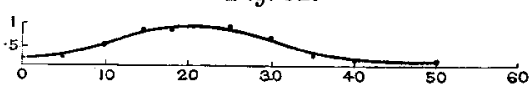

Illumination-Corve $\mathrm{C}$, Fig. 30 , Reduced to fit the $\cos ^{4} \theta$ gurve.

the test, below the average. A plan of the portion of the street, corrected from the ordnance map, is given in Fig. 34. The three 
lamps are marked $\mathrm{A}, \mathrm{B}, \mathrm{C}$, and a linejacross the street at the minimum is marked DE. The illumination-curves in Figs. 32 show the actual readings. Starting from $A$, the illumination was $0 \cdot 1$ candlefoot at the foot of the lamp-post. A few seconds later, at a

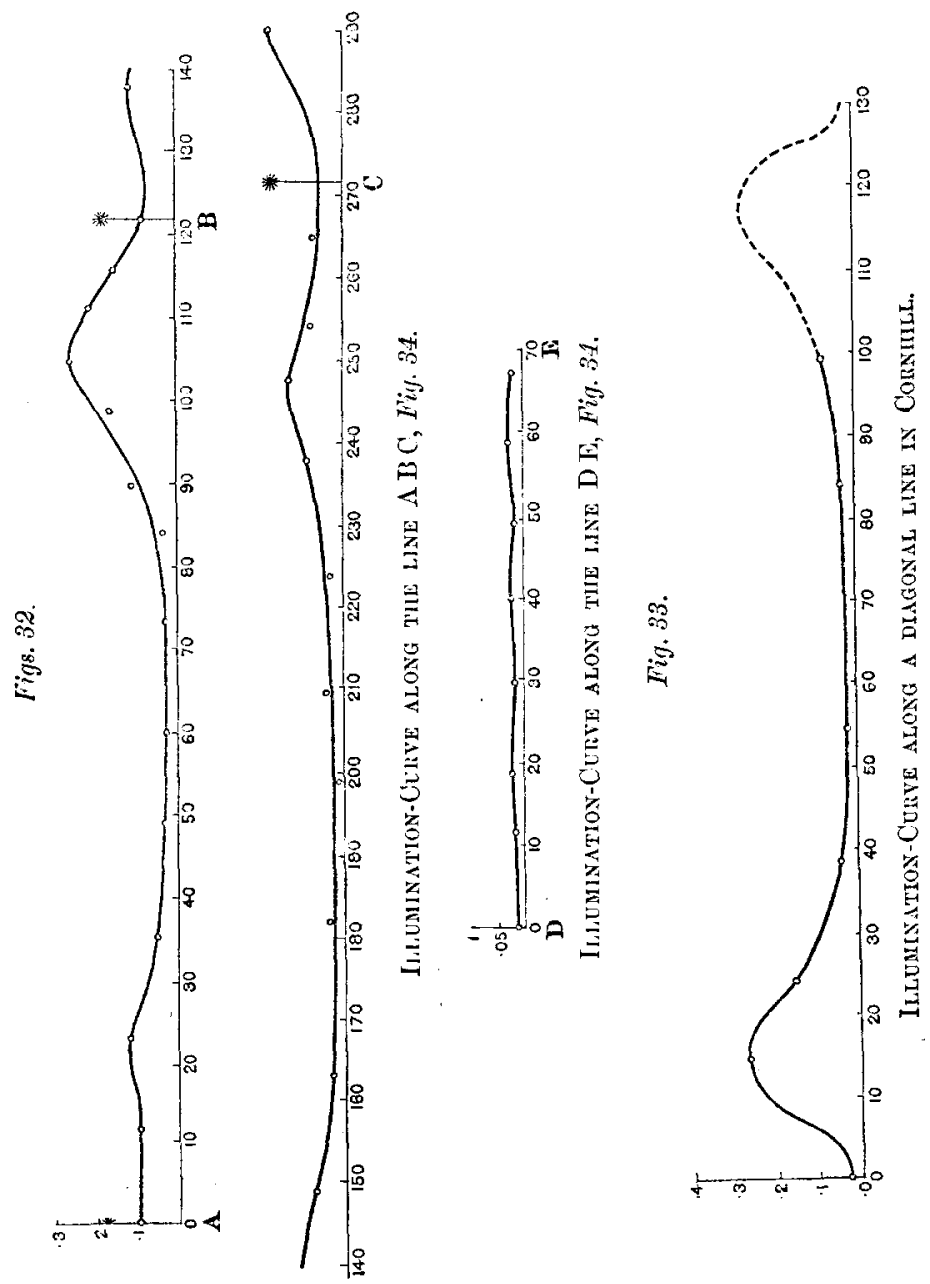

distance of 11 feet, before another reading could be taken, the lamp fed, and the reading at this point was the same. The measurements were continued without interruption, and the early ones probably represent the lowest illumination that is to be found 
under these circumstances. On approaching $B$ the light was good, and was a fair average of what the Author has found in some dozen or more tests. On starting towards C, lamp B fed, and C appears to have been below the average of this series of measurements. The measurements of distance were made with a tape; the assistance of the police-constables, kindly provided by

Fig. 34.

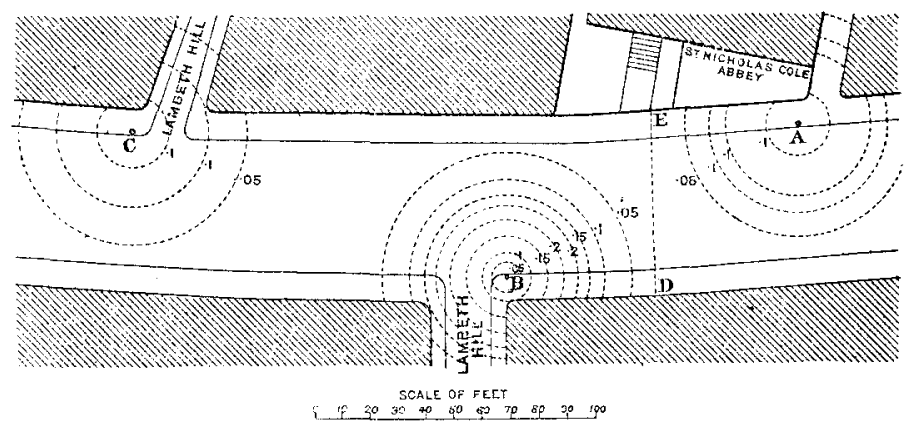

Contour-Lines of Eqcal Itudmination in Queen Victoria Street, London.

Fig. 3.).

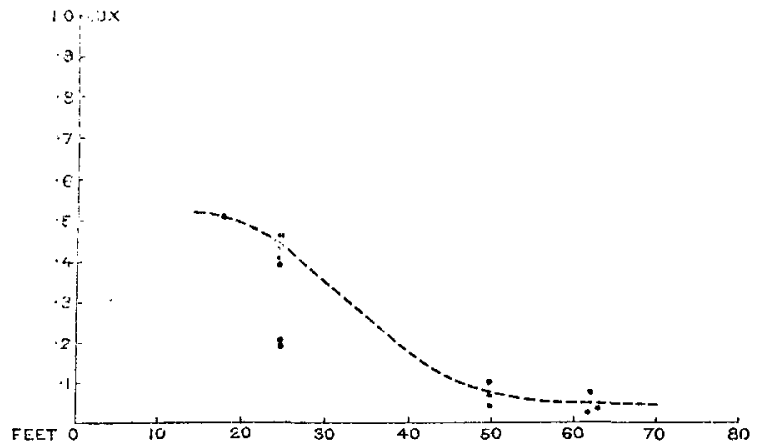

Variocs Measurements of Irlumination of Arc-Lamps in t'he City of London, made by Mr. Preece.

Inspector Fraser, greatly facilitated the work, by diverting the traffic and by keeping off bystanders. The contour-lines are practically circles. It has been assumed, in the circles drawn in Fig. 34, that lamp C was burning well. If the contour of 0.04 candle-foot had been drawn, it would probably have been of the hour-glass kind, just looping on to the pavement near the minimum. The arc-lamps appeared to be about 17 feet 8 inches 
high, and the distance of the lamps apart was about 6.5 times their height.

A number of measurements, made under the direction of Mr. Preece, with his photometer, on different dates, and in different parts of Queen Victoria Street, are represented in Fig. 35, and an attempt has been made to draw a curve among them. The ordinates are given as decimals of a lux.

\section{Whitehali.}

On the 11th of February, 1892, a careful survey of Whitehall was made. Fig. 36 is a plan of the part of the street between

Fig. 36 .

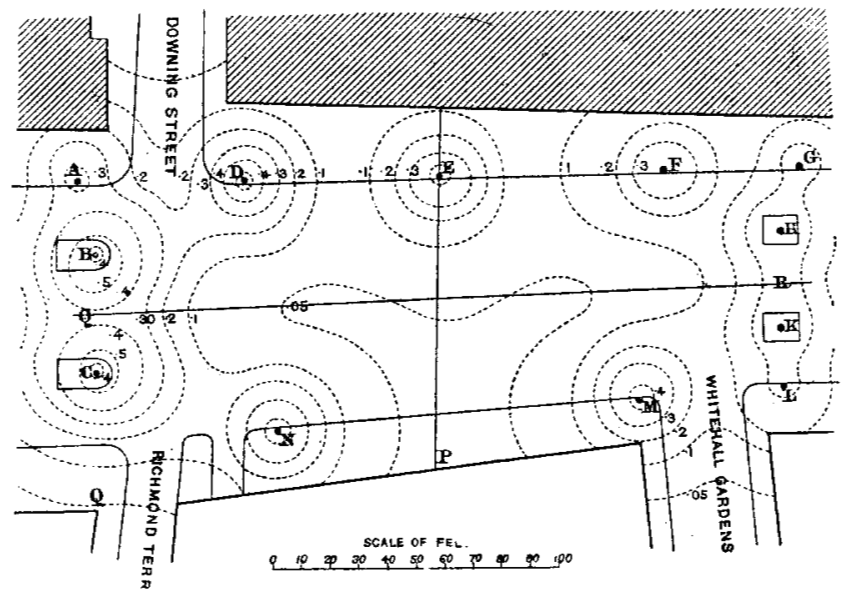

Contoch-Lines of Equal Illumination in Whitehall, Westminster.

Downing Street and Whitehall Gardens. The gas-lamps are marked A to N, both on the plan and on Figs. 37, 38, 39, and 40, which give the illumination-curves along the measured lines. Only a single reading near the minimum has been suppressed, being obviously wrong. The Author has been informed by Messrs. Sugg \& Co. that the lamps are of the following description :The small side lamps are "Whitehall" pattern, and are: 90 candle-power, consuming 20 cubic feet per hour. The large'lamps are of the "Westminster" pattern, of 270 candle-power, consuming 50 cubic feet per hour.

[THE INST. C.E. VOL. CX.] 
The illumination-curves show very clearly the effect of the shadow below the ordinary lamps. The large lamps at the "refuges" are provided with reflectors, which greatly lessen the shadow. Either because the transverse line AQ was not taken
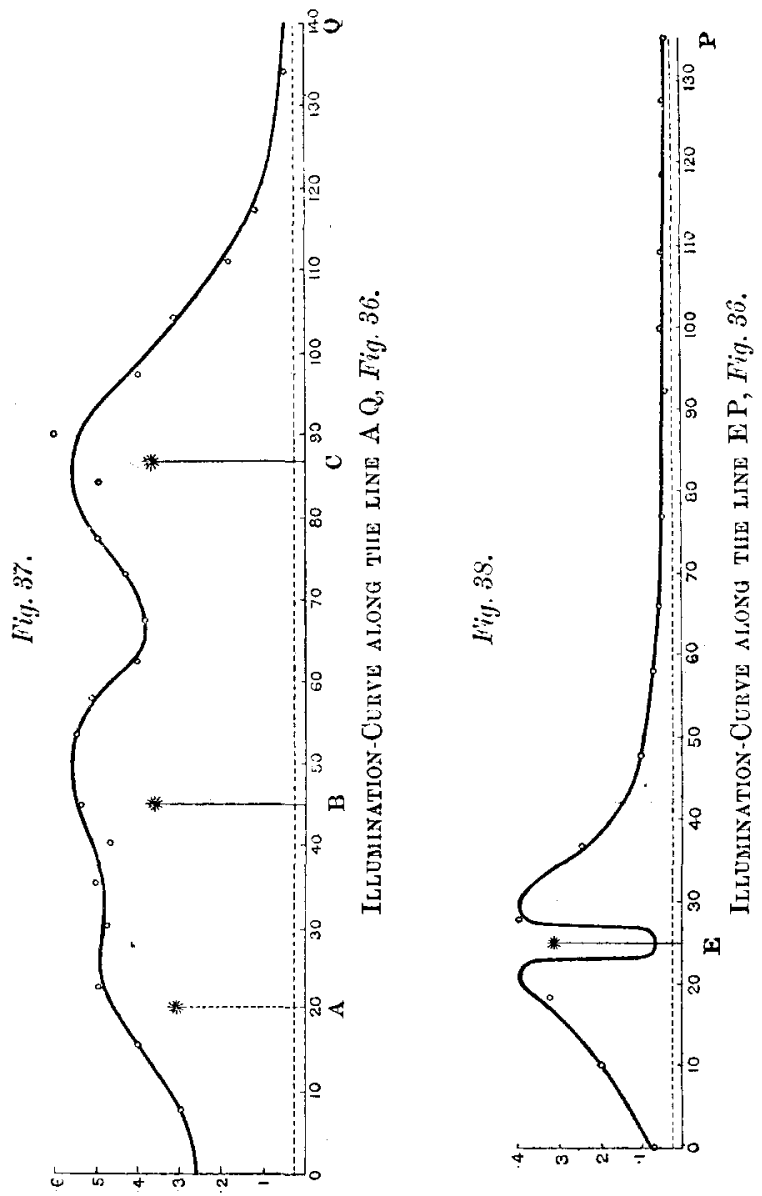

immediately below the lamps B and C, or by some error in the measurements, the shadow below these lamps does not appear plainly. From these illumination-curves may be seen the gradual rise of the minimum between $A$ and $D$ and between $F$ and $G$, owing to the effect of the lamps at the refuges. The moon was 
nearly full, and the sky was cloudless. ${ }^{1}$ The dotted line represents the illumination 0.025 due to moonlight. The survey was completed at about 11 P.M. From these curves the contour-lines in Fig. 36 were drawn, and from these contour-lines a model has been constructed by the Author, on the scale of 20 feet to an inch in plan, and 1 candle-foot to an inch in elevation.

Figs. 39.

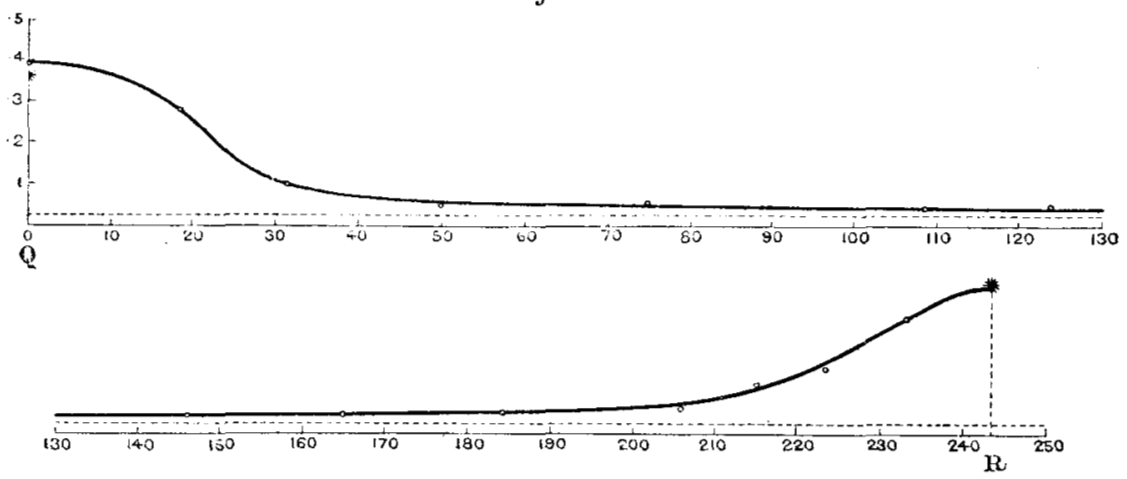

Illcyination-Curve along the lise Q R, Fig. 3 j.
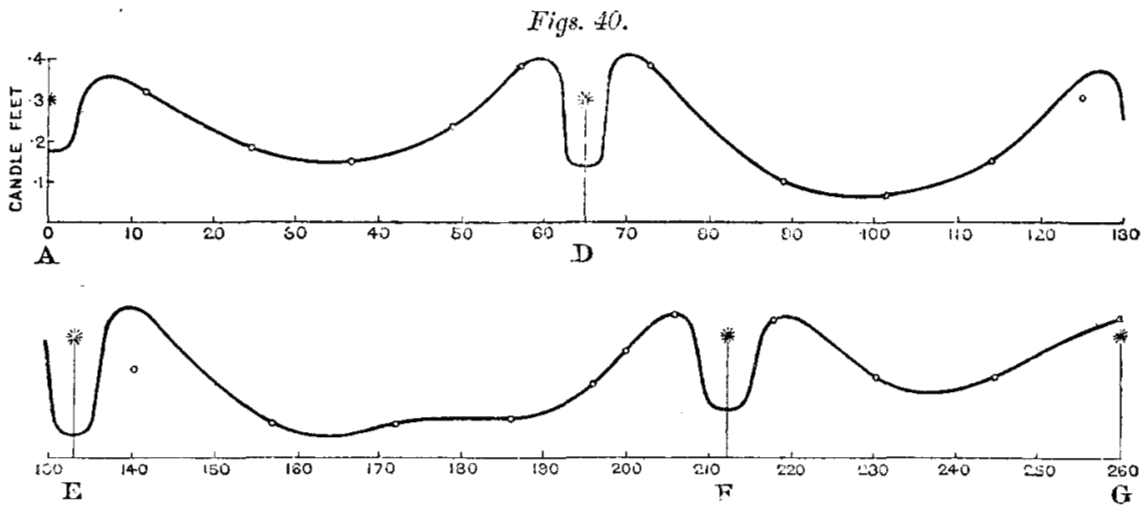

Illumisatton-Curve along the lise A G, Fig. 36 .

The difference between the illumination in Queen Victoria Street and in Whitehall was so very much less than the Author expected, that he repeated the measurements of the maxima and

1 Several attempts were made to measure street-illumination on moonlight uights when clouds were drifting over the sky. Although attempts were mado to screen the photometer from the moon, the measurements were very irregular. 
minima at Whitehall on the 25th of February, and proceeded at once to Queen Victoria Street, where he made twelve measurements of maxima and minima. He then returned to Whitehall and repeated the observations, thus ensuring that no error could be caused by variation in the power of the electric-lamp in the photometer. The measurements were in accordance with the results which have been given. An attempt to read a Bellows' French dictionary at different parts of the street seemed to show that the light in Queen Victoria Street was rather more useful, but the lighting in Whitehall is certainly less dazzling.

\section{Ordixary Streets, Theatre-Ligirtixg, \&c.}

Measurements of the illumination in streets lighted by the ordinary "5-feet" gas-lamp were made on several occasions. The

Fig. 41 .

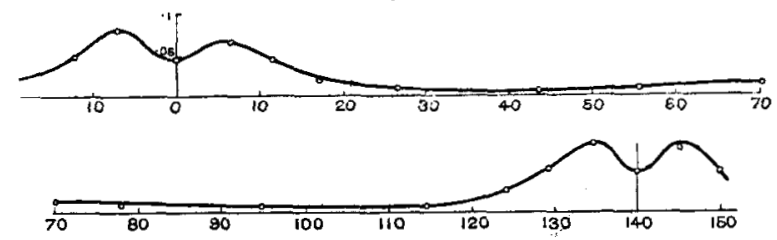

Inlcuination-Curte aiong the Cork of the Foot-Paveuent of Great Gronge Street, Westminster.

illumination is so very feeble that exact measurement is very difficult. The maximum rarely exceeded 0.9 candle-foot. The illumination near the foot of an ordinary gas-lamp is very irregular, and is much cut up by shadows of the lantern frame. Fig. 41 is the illumination-curve along the curb of the foot-pavement of Great George Street, Westminster. A slight increase midway between the lamps is due to a lamp on the opposite side of the street. The minima were about 0.005 candle-foot, an illumination a little greater than the value calculated by the cosine-cubed law. This is probably due to the reflection from surrounding buildings, or to general diffused light.

The illumination on the stage of the Lyric Theatre during the performance of "La Cigale" was $3 \cdot 8$ candle-feet without the arcor lime-lights. On the stage of the Prince of Wales 'Theatre during the performance of "Maid Marian" the illumination was 2.9 candle-feet. The illumination in the trains of the Metropolitan 
and District Railways was measured on many occasions, and varied from 0.3 to 0.9 candle-foot, the photometer being held breast-high.

\section{Characteristic Curyes.}

The results of the above-described measurements are summed up in Fig. 42 as characteristic curves. The ordinates are candle-

Fig. 42 .

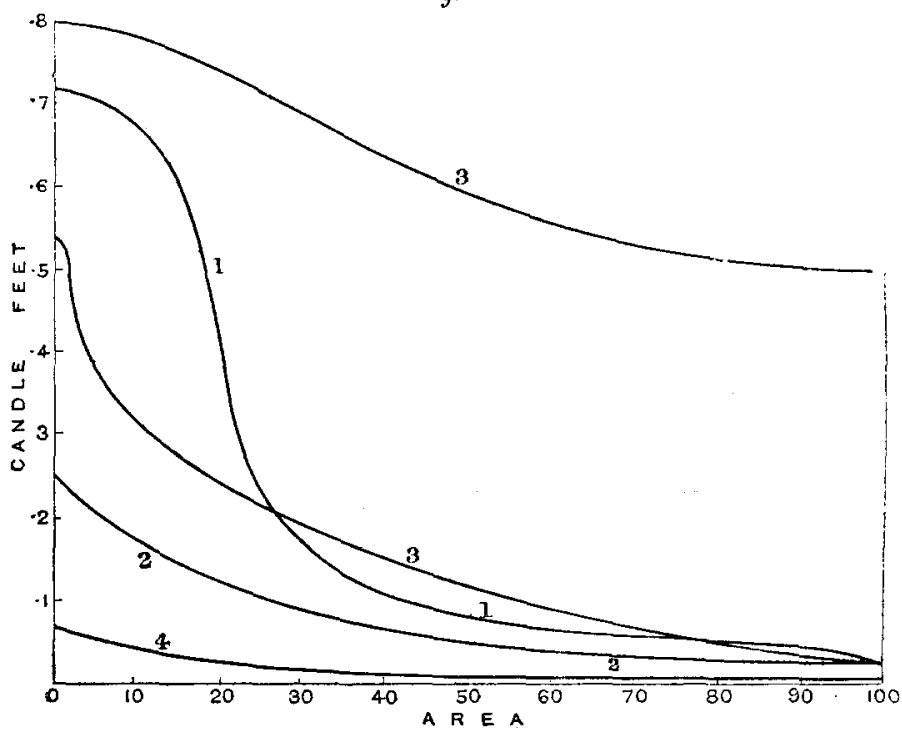

Charaqtertstic Curyes on Preceding Cases.

feet, and the horizontal scale is a percentage scale of areas. The maximum is 100. No. 1 is the characteristic of Queen Victoria Street, on the assumption that the lights are all burning at their best, as in curve C, Fig. 30. No. 2 is the characteristic of the same street, on the assumption that the lamps are at their worst, having just fed. No. 3 is the characteristic of Whitehall, the moonlight having been deducted. It appears that about one-half the area is better lighted than Queen Victoria Street. No. 4 is the characteristic of an ordinary gas-lit street. No. 5 is the characteristic, estimated approximately only, of the Architecture Court of the South Kensington Museum. 
Conclusion.

The Author, in conclusion, desires to record his indebtedness to Mr. Winny for assistance in experimental work and checking calculations; to Messrs. J. Leggat, J. E. Pierce, and W. G. Wallace, students at Finsbury Technical College, for their assistance in street-lighting measurements, which were sometimes continued until a late hour; to the Mining and General Electric-Lamp Company for alterations to photometers, for the loan of Lithanode batteries, and for the charging of the same on many occasions; to Mr. Preece for procuring him permission to make measurements in various public buildings; as well as to the police, without whose assistance the street-work would have been impossible. 


\section{APPENDIX.}

Each of the following combinations is equal to one bougie-metre, or one-tenth of a lux.

TABle I.-Round Numbers of Candele-Power.

\begin{tabular}{|c|c|c|c|c|c|c|c|}
\hline $\begin{array}{l}\text { Candle- } \\
\text { power. }\end{array}$ & Feet. & $\begin{array}{l}\text { Candle- } \\
\text { power. }\end{array}$ & Feet. & $\begin{array}{l}\text { Candle- } \\
\text { power. }\end{array}$ & Feet. & $\begin{array}{l}\text { Candle- } \\
\text { power. }\end{array}$ & Feet. \\
\hline $0 \cdot 01$ & $0 \cdot 3350$ & $1 \cdot 6$ & $4 \cdot 235$ & 13 & $12 \cdot 07$ & 40 & $21 \cdot 17$ \\
\hline 0.02 & 0.4735 & $1 \cdot 8$ & $4 \cdot 490$ & 14 & $12 \cdot 52$ & 42 & $21 \cdot 70$ \\
\hline 0.03 & $0 \cdot 5800$ & $2 \cdot 0$ & $4 \cdot 735$ & 15 & $12 \cdot 96$ & 44 & $22 \cdot 20$ \\
\hline $0 \cdot 04$ & $0 \cdot 6700$ & $2 \cdot 5$ & $5 \cdot 290$ & 16 & $13 \cdot 40$ & 46 & $22 \cdot 70$ \\
\hline $0 \cdot 0 \tilde{5}$ & $0 \cdot 7490$ & $3 \cdot 0$ & $5 \cdot 800$ & 17 & $13 \cdot 80$ & 48 & $23 \cdot 20$ \\
\hline $0 \cdot 06$ & 0.8200 & $3 \cdot 5$ & $6 \cdot 260$ & 18 & $14 \cdot 21$ & 50 & $23 \cdot 68$ \\
\hline $0 \cdot 07$ & $0 \cdot 8860$ & $4 \cdot 0$ & $6 \cdot 700$ & 19 & $14 \cdot 60$ & 60 & $25 \cdot 94$ \\
\hline 0.08 & 0.9470 & $4 \cdot 5$ & $7 \cdot 100$ & 20 & $14 \cdot 97$ & 70 & $28 \cdot 00$ \\
\hline 0.09 & $1 \cdot 0040$ & $5 \cdot 0$ & $7 \cdot 490$ & 21 & $15 \cdot 34$ & 80 & $29 \cdot 95$ \\
\hline $0 \cdot 10$ & $1 \cdot 0580$ & $5 \cdot 5$ & $7 \cdot 860$ & 22 & $15 \cdot 70$ & 90 & $31 \cdot 75$ \\
\hline $0 \cdot 20$ & $1 \cdot 4970$ & $6 \cdot 0$ & $8 \cdot 200$ & 23 & $16 \cdot 05$ & 100 & $33 \cdot 50$ \\
\hline $0 \cdot 30$ & $1 \cdot 8350$ & $6 \cdot 5$ & $8 \cdot 540$ & 24 & $16 \cdot 40$ & 200 & $47 \cdot 35$ \\
\hline $0 \cdot 40$ & $2 \cdot 1180$ & $7 \cdot 0$ & $8 \cdot 850$ & 25 & $16 \cdot 74$ & 300 & $58 \cdot 00$ \\
\hline 0.50 & $2 \cdot 3680$ & $7 \cdot 5$ & $9 \cdot 170$ & 26 & $17 \cdot 07$ & 400 & $67 \cdot 00$ \\
\hline $0 \cdot 60$ & $2 \cdot 5940$ & $8 \cdot 0$ & $9 \cdot 470$ & 28 & $17 \cdot 71$ & 500 & $74 \cdot 90$ \\
\hline $0 \cdot 70$ & $2 \cdot 8000$ & $8 \cdot 5$ & $9 \cdot 760$ & 29 & $18 \cdot 02$ & 600 & $82 \cdot 00$ \\
\hline $0 \cdot 80$ & $2 \cdot 9950$ & $9 \cdot 0$ & $10 \cdot 040$ & 30 & $18 \cdot 34$ & 700 & $88 \cdot 60$ \\
\hline $0 \cdot 90$ & $3 \cdot 1750$ & $9 \cdot 5$ & $10 \cdot 032$ & 32 & $18 \cdot 94$ & 800 & $94 \cdot 70$ \\
\hline$I \cdot 00$ & $3 \cdot 3500$ & $10 \cdot 0$ & $10 \cdot 580$ & 34 & $19 \cdot 62$ & 900 & $100 \cdot 04$ \\
\hline $1 \cdot 20$ & $3 \cdot 6700$ & $11 \cdot 0$ & $11 \cdot 110$ & 36 & $20 \cdot 08$ & 1,000 & $105 \cdot 80$ \\
\hline$I \cdot 40$ & $3 \cdot 9600$ & $12 \cdot 0$ & $11 \cdot 600$ & 38 & $20 \cdot 63$ & 2,000 & $149 \cdot 70$ \\
\hline
\end{tabular}

Table II.-Round Numbers of Feet.

\begin{tabular}{|c|c|c|c|c|c|c|c|}
\hline $\begin{array}{l}\text { Candle- } \\
\text { power. }\end{array}$ & Feet. & $\begin{array}{l}\text { Candle- } \\
\text { power. }\end{array}$ & Feet. & $\begin{array}{l}\text { Candle- } \\
\text { power. }\end{array}$ & Feet. & $\begin{array}{l}\text { Candle- } \\
\text { power. }\end{array}$ & Feet. \\
\hline 0.02235 & 0.5 & $3 \cdot 770$ & $6 \cdot 5$ & $20 \cdot 08$ & 15 & $65 \cdot 0$ & 27 \\
\hline $0 \cdot 08945$ & $1 \cdot 0$ & $4 \cdot 375$ & $7 \cdot 0$ & $22 \cdot 84$ & 16 & $70 \cdot 0$ & 28 \\
\hline $0 \cdot 20080$ & $1 \cdot 5$ & $5 \cdot 020$ & $7 \cdot 5$ & $25 \cdot 8$ & 17 & $75 \cdot 0$ & 29 \\
\hline $0 \cdot 35700$ & $2 \cdot 0$ & $5 \cdot 710$ & $8 \cdot 0$ & $28 \cdot 9$ & 18 & $80 \cdot 4$ & 30 \\
\hline $0 \cdot 55900$ & $2 \cdot 5$ & $6 \cdot 450$ & $8 \cdot 5$ & $32 \cdot 2$ & 19 & $109 \cdot 3$ & 35 \\
\hline $0 \cdot 80400$ & $3 \cdot 0$ & $7 \cdot 240$ & $9 \cdot 0$ & $35 \cdot 7$ & 20 & $143 \cdot 0$ & 40 \\
\hline $1 \cdot 09300$ & $3 \cdot 5$ & $8 \cdot 050$ & $9 \cdot 5$ & $39 \cdot 4$ & 21 & $181 \cdot 0$ & 45 \\
\hline $1 \cdot 43000$ & $4 \cdot 0$ & $8 \cdot 940$ & $10 \cdot 0$ & $43 \cdot 2$ & 22 & $223 \cdot 5$ & 50 \\
\hline $\mathbf{1} \cdot 81000$ & $4 \cdot 5$ & $90 \cdot 800$ & $11 \cdot 0$ & $47 \cdot 2$ & 23 & $321 \cdot 5$ & 60 \\
\hline $2 \cdot 23500$ & $\tilde{\mathbf{5}} \cdot 0$ & $12 \cdot 850$ & $12 \cdot 0$ & $51 \cdot 5$ & 24 & $437 \cdot 0$ & 70 \\
\hline $2 \cdot 70000$ & $5 \cdot 5$ & $15 \cdot 100$ & $13 \cdot 0$ & $55 \cdot 8$ & 25 & $571 \cdot 0$ & 80 \\
\hline $3 \cdot 21500$ & $6 \cdot 0$ & $17 \cdot 500$ & $14 \cdot 0$ & $60 \cdot 4$ & 26 & $894 \cdot 0$ & 100 \\
\hline
\end{tabular}


Table III.-Round Nunbers of $\operatorname{Cos}^{3} \theta$.

\begin{tabular}{|c|c|c|c|c|c|c|c|}
\hline $\operatorname{Cos}^{3} \theta$ & $\operatorname{Cos} \theta$ & $\theta$. & $\operatorname{Tan} \theta$ & $\cos ^{3} \theta$. & $\operatorname{Cos} \theta$. & $\theta$. & $\operatorname{Tan} \theta$ \\
\hline & & & & & & ( & \\
\hline $0 \cdot 995$ & 0.9983 & 320 & $0 \cdot 0582$ & $0 \cdot 360$ & $0 \cdot 7114$ & $44 \quad 39$ & 0.9878 \\
\hline 0.990 & $0 \cdot 9966$ & 4. 43 & 0.0825 & $0 \cdot 340$ & $0 \cdot 6980$ & 4544 & $1 \cdot 0260$ \\
\hline 0.980 & 0.9933 & 638 & 0.1163 & 0.320 & 0.6840 & 4651 & $1 \cdot 0670$ \\
\hline 0.960 & 0.9865 & 925 & $0 \cdot 1658$ & $0 \cdot 300$ & 0.6694 & 4759 & $1 \cdot 1100$ \\
\hline 0.940 & 0.9796 & 1135 & $0 \cdot 2058$ & 0.280 & $0 \cdot 6542$ & 498 & $1 \cdot 1560$ \\
\hline 0.920 & 0.9726 & 1327 & 0.2392 & $0 \cdot 260$ & 0.6382 & 5020 & $1 \cdot 2060$ \\
\hline 0.900 & 0.9655 & 155 & 0.2695 & $0 \cdot 240$ & $0 \cdot 6214$ & 5135 & $1 \cdot 2610$ \\
\hline 0.880 & 0.9583 & 1636 & 0.2981 & 0.220 & 0.6037 & 5252 & $1 \cdot 3210$ \\
\hline 0.860 & 0.9510 & 181 & & 0.200 & & $54 \quad 13$ & $1 \cdot 3870$ \\
\hline $0 \cdot 840$ & $0 \cdot 9435$ & 1921 & 0.3512 & $0 \cdot 190$ & 0.5749 & 5454 & $1 \cdot 4230$ \\
\hline 0.820 & 0.9360 & 2036 & 0.3759 & $0 \cdot 180$ & 0.5646 & 5537 & $1 \cdot 4610$ \\
\hline $0 \cdot 800$ & 0.9283 & 2150 & 0.4 & 0.170 & 0 . & 5621 & 6020 \\
\hline $0 \cdot 780$ & 0.9205 & 230 & 0.4245 & $0 \cdot 160$ & 0.5429 & 577 & $\bar{I} \cdot 5470$ \\
\hline 0.760 & 0.9126 & 248 & 0.4480 & $0 \cdot 150$ & 0.5313 & 5754 & $1 \cdot 5940$ \\
\hline 0.740 & $0 \cdot 9045$ & 2515 & 0.4 & $0 \cdot 140$ & 0.5192 & 5843 & $1 \cdot 6460$ \\
\hline 0.720 & 0.8963 & 2620 & 0.4 & $0 \cdot 130$ & 0.5065 & 5934 & $1 \cdot 7020$ \\
\hline 0.700 & 0.8879 & 2423 & 0.5180 & $0 \cdot 120$ & 0.4932 & 6027 & $1 \cdot 7640$ \\
\hline 0.680 & 0.8794 & 2826 & 0.5 & $0 \cdot 110$ & 0.4791 & 6122 & $1 \cdot 8320$ \\
\hline $0 \cdot 660$ & 0.8707 & 2928 & & $0 \cdot 100$ & 0.4642 & 6220 & $1 \cdot 9070$ \\
\hline $0 \cdot 640$ & 0.8618 & 3029 & & 0.090 & 0.4481 & 6323 & $1 \cdot 9950$ \\
\hline 0.620 & 0.8527 & 3130 & 0.6128 & 0.080 & 0.4309 & 6428 & $2 \cdot 0930$ \\
\hline 0.600 & 0.84 & 3230 & & 0. & 0. & 6540 & $2 \cdot 2110$ \\
\hline 0.580 & 0.8340 & 3329 & 0.6615 & 0.060 & 0.3915 & 6657 & $2 \cdot 3500$ \\
\hline 0.560 & 0.8243 & 3429 & 0.6868 & 0.050 & 0.3684 & 6823 & $2 \cdot 5240$ \\
\hline $0 \cdot 540$ & 0.8143 & 3529 & & 0. & $0 \cdot 3$ & 700 & $2 \cdot 7470$ \\
\hline 0.520 & 0.8041 & 3629 & 0.7395 & 0.030 & 0.3107 & 7154 & $3 \cdot 0590$ \\
\hline 0.500 & 0.7937 & 3728 & 0.7664 & $0 \cdot 020$ & 0.2714 & $74 \quad 15$ & $3 \cdot 5460$ \\
\hline $0 \cdot 480$ & $0 \cdot 7830$ & 3828 & 0.7945 & 0.010 & 0.2154 & 7734 & $4 \cdot 5360$ \\
\hline 0.460 & 0.7719 & 3928 & 0.8234 & 0.008 & 0.20 & 7827 & $4 \cdot 8930$ \\
\hline 0.440 & $0 \cdot 7606$ & 4029 & & 0.005 & 0.1 & 809 & $\overline{5} \cdot 7590$ \\
\hline $0 \cdot 420$ & 0.7489 & 4130 & 0.8847 & 0.002 & $0 \cdot 1260$ & 8246 & $7 \cdot 8800$ \\
\hline $0 \cdot 400$ & $0 \cdot 7368$ & 4232 & 0.9174 & 0.001 & $0 \cdot 1000$ & 8415 & $9 \cdot 9310$ \\
\hline 0.380 & 0.7243 & 4335 & 0.9517 & & & & \\
\hline
\end{tabular}

Table IV.-Rodxd Numbers of $\theta$.

\begin{tabular}{|c|c|c|c|c|c|c|c|}
\hline$\theta$. & $\operatorname{Cos}^{3} \theta$. & $\theta$. & $\cos ^{3} \theta$ & $\theta$. & $\operatorname{Cos}^{3} \theta$ & $\theta$. & $\operatorname{Cos}^{3} \theta$. \\
\hline 2 & 0.9982 & 22 & 0.7971 & 42 & $0 \cdot 4103$ & 62 & $0 \cdot 103440$ \\
\hline 4 & 0.9928 & 24 & 0.7614 & 44 & $0 \cdot 3722$ & 64 & 0.084258 \\
\hline 5 & 0.9886 & 25 & 0.7444 & 45 & $0 \cdot 3585$ & 65 & 0.075474 \\
\hline 6 & 0.9836 & 26 & 0.7261 & 46 & 0.3353 & 66 & $0 \cdot 067270$ \\
\hline 8 & 0.9712 & 28 & 0.6882 & 48 & 0.2995 & 68 & 0.052606 \\
\hline 10 & 0.9551 & 30 & $0 \cdot 6495$ & 50 & $0 \cdot 2656$ & 70 & 0.040002 \\
\hline 12 & $0 \cdot 9357$ & 32 & 0.6098 & 52 & 0.2334 & 72 & $0 \cdot 029504$ \\
\hline 14 & 0.9135 & 34 & 0.5697 & 54 & $0 \cdot 2031$ & 75 & $0 \cdot 01733 t$ \\
\hline 15 & 0.9011 & 35 & 0.5495 & 55 & 0.1888 & 80 & 0.005232 \\
\hline 16 & 0.8883 & 36 & 0.5295 & 56 & $0 \cdot 1754$ & 85 & $0 \cdot 000662$ \\
\hline 18 & $0 \cdot 8603$ & 38 & 0.4893 & 58 & 0.1488 & & \\
\hline 20 & 0.8271 & 40 & 0.4494 & 60 & $0 \cdot 1250$ & & \\
\hline
\end{tabular}


TABLe V.

\begin{tabular}{|c|c|c|c|c|c|}
\hline $\operatorname{Tan} \theta$ & $\theta$. & $\operatorname{Cos} \theta$. & $\operatorname{Cos}^{2} \theta$. & $\operatorname{Cos}^{3} \theta$ & $\operatorname{Cos}^{4} \theta$ \\
\hline & ' & & & & \\
\hline $0 \cdot 05$ & 252 & 0.9987 & 0.9970 & $0 \cdot 99600$ & 0.991000 \\
\hline $0 \cdot 10$ & 543 & 0.9950 & $0 \cdot 9900$ & 0.98500 & $0 \cdot 982000$ \\
\hline $0 \cdot 20$ & 1119 & 0.9806 & 0.9600 & $0 \cdot 94300$ & $0 \cdot 922000$ \\
\hline $0 \cdot 30$ & 1642 & $0 \cdot 9578$ & $0 \cdot 9170$ & 0.87900 & $0 \cdot 841000$ \\
\hline $0 \cdot 40$ & 2149 & $0 \cdot 9284$ & $0 \cdot 8620$ & $0 \cdot 80000$ & $0 \cdot 743000$ \\
\hline $0 \cdot 50$ & 2634 & 0.8944 & $0 \cdot 8000$ & $0 \cdot 71500$ & $0 \cdot 640000$ \\
\hline $0 \cdot 60$ & 3058 & $0 \cdot 8575$ & $0 \cdot 7350$ & $0 \cdot 63000$ & 0.540000 \\
\hline $0 \cdot 70$ & 350 & $0 \cdot 8191$ & $0 \cdot 6710$ & 0.54900 & $0 \cdot 450000$ \\
\hline $0 \cdot 80$ & 3840 & $0 \cdot 7808$ & $0 \cdot 6100$ & 0.47600 & $0 \cdot 372000$ \\
\hline $0 \cdot 90$ & 420 & 0.7431 & $0 \cdot 5520$ & 0.41000 & $0 \cdot 305000$ \\
\hline $1 \cdot 00$ & 450 & $0 \cdot 7071$ & $0 \cdot 5000$ & $0 \cdot 35300$ & $0 \cdot 250000$ \\
\hline $1 \cdot 10$ & 4744 & $0 \cdot 6726$ & $0 \cdot 4520$ & $0 \cdot 30500$ & $0 \cdot 204000$ \\
\hline $1 \cdot 20$ & $\begin{array}{lll}50 & 12\end{array}$ & $0 \cdot 6401$ & $0 \cdot 4100$ & $0 \cdot 26200$ & $0 \cdot 168000$ \\
\hline $1 \cdot 30$ & $52 \quad 26$ & 0.6097 & 0.3710 & $0 \cdot 22600$ & $0 \cdot 138000$ \\
\hline $1 \cdot 40$ & 5428 & 0.5812 & $0 \cdot 3380$ & $0 \cdot 19600$ & $0 \cdot 114000$ \\
\hline $1 \cdot 50$ & $\begin{array}{ll}36 & 19\end{array}$ & $0 \cdot 5546$ & $0 \cdot 3070$ & $0 \cdot 17100$ & $0 \cdot 094300$ \\
\hline $1 \cdot 60$ & 580 & 0.5299 & $0 \cdot 2810$ & 0.14900 & 0.079000 \\
\hline $1 \cdot 70$ & 5933 & $0 \cdot 5068$ & $0 \cdot 2570$ & $0 \cdot 13000$ & 0.066000 \\
\hline $1 \cdot 80$ & 6057 & 0.4856 & $0 \cdot 2360$ & $0 \cdot 11400$ & 0.055700 \\
\hline $1 \cdot 90$ & $62 \quad 15$ & 0.4656 & $0 \cdot 2170$ & $0 \cdot 10100$ & $0 \cdot 047100$ \\
\hline $2 \cdot 00$ & 6327 & $0 \cdot 4470$ & $0 \cdot 2000$ & $0 \cdot 08930$ & $0 \cdot 040000$ \\
\hline $2 \cdot 20$ & 6534 & 0.4136 & $0 \cdot 1710$ & 0.07090 & 0.029200 \\
\hline $2 \cdot 40$ & 6723 & $0 \cdot 3846$ & $0 \cdot 1480$ & 0.05680 & 0.021900 \\
\hline $2 \cdot 60$ & 6858 & $0 \cdot 3589$ & $0 \cdot 1290$ & $0 \cdot 04630$ & $0 \cdot 016600$ \\
\hline $2 \cdot 80$ & 7021 & $0 \cdot 3363$ & $0 \cdot 1130$ & 0.03800 & $0 \cdot 012800$ \\
\hline $3 \cdot 00$ & 7134 & $0 \cdot 3162$ & $0 \cdot 1000$ & 0.03160 & $0 \cdot 010000$ \\
\hline $3 \cdot 20$ & 7239 & 0.2982 & 0.0888 & 0.02650 & $0 \cdot 007880$ \\
\hline $3 \cdot 40$ & 7337 & $0 \cdot 2821$ & $0 \cdot 0795$ & 0.02240 & 0.006320 \\
\hline $3 \cdot 50$ & 743 & $0 \cdot 2748$ & $0 \cdot 0756$ & 0.02080 & 0.005710 \\
\hline $4 \cdot 00$ & 7558 & 0.2425 & $0 \cdot 0597$ & 0.01420 & 0.003560 \\
\hline $4 \cdot 50$ & 7729 & 0.2167 & $0 \cdot 0468$ & 0.01020 & 0.002190 \\
\hline $5 \cdot 00$ & 7842 & $0 \cdot 1959$ & $0 \cdot 0384$ & $0 \cdot 00752$ & 0.001470 \\
\hline $5 \cdot 50$ & 7942 & $0 \cdot 1788$ & $0 \cdot 0320$ & $0 \cdot 00573$ & 0.001020 \\
\hline $6 \cdot 00$ & $80 \quad 33$ & $0 \cdot 1642$ & 0.0269 & 0.00441 & $0 \cdot 000724$ \\
\hline $6 \cdot 50$ & $81 \quad 16$ & $0 \cdot 1518$ & 0.0231 & $0 \cdot 00851$ & $0 \cdot 000534$ \\
\hline $7 \cdot 00$ & 8153 & $0 \cdot 1412$ & 0.0199 & $0 \cdot 00280$ & 0.000396 \\
\hline $7 \cdot 50$ & 8224 & 0.1323 & 0.0174 & $0 \cdot 00230$ & $0 \cdot 000303$ \\
\hline $8 \cdot 00$ & 8253 & $0 \cdot 1239$ & 0.0154 & 0.00190 & 0.000237 \\
\hline $8 \cdot 50$ & $83 \quad 17$ & $0 \cdot 1169$ & $0 \cdot 0137$ & 0.00160 & 0.000188 \\
\hline $9 \cdot 00$ & 8340 & $0 \cdot 1103$ & 0.0121 & $0 \cdot 00133$ & 0.000146 \\
\hline $9 \cdot 50$ & 840 & $0 \cdot 1045$ & 0.0109 & $0 \cdot 00113$ & 0.000119 \\
\hline $10 \cdot 00$ & $84 \quad 18$ & 0.0993 & 0.0099 & $0 \cdot 00099$ & 0.000980 \\
\hline
\end{tabular}

